\title{
Skill Assessment of an Atmosphere-Wave Regional Coupled Model over the East China Sea with a Focus on Typhoons
}

\author{
Delei Li ${ }^{1,2,3}$, Joanna Staneva ${ }^{4}$, Sebastian Grayek ${ }^{4}$, Arno Behrens ${ }^{4}$, Jianlong Feng ${ }^{5}$ and \\ Baoshu Yin 1,2,3,6,* \\ 1 CAS Key Laboratory of Ocean Circulation and Waves, Institute of Oceanology, Chinese Academy of Sciences, \\ Qingdao 266071, China; deleili@qdio.ac.cn \\ 2 Center for Ocean Mega-Science, Chinese Academy of Sciences, Qingdao 266071, China \\ 3 Pilot National Laboratory for Marine Science and Technology, Qingdao 266237, China \\ 4 Institute of Coastal Research, Helmholtz Zentrum Geesthacht, Geesthacht 21502, Germany; \\ Joanna.Staneva@hzg.de (J.S.); Sebastian.Grayek@hzg.de (S.G.); arno.behrens@hzg.de (A.B.) \\ 5 College of Marine and Environmental Sciences, Tianjin University of Science and Technology, \\ Tianjin 300457, China; fjl181988@tust.edu.cn \\ 6 College of Earth and Planetary Sciences, University of Chinese Academy of Sciences, Beijing 100864, China \\ * Correspondence: bsyin@qdio.ac.cn; Tel.: +86-053282898502
}

Received: 22 January 2020; Accepted: 1 March 2020; Published: 3 March 2020

\begin{abstract}
This study performed several sensitivity experiments to investigate the impact of atmosphere-wave coupling on the simulated wind and waves over the East China Sea (ECS) with a focus on typhoon events. These experiments include stand-alone regional atmosphere model (CCLM) simulations, stand-alone spectral wave model (WAM) simulations driven by the regional atmospheric model CCLM or ERA5 reanalysis, and two-way (CCLM-WAM) coupled simulations. We assessed the simulated wind speed and significant wave height against in situ observations and remote sensing data and focused on typhoon events in 2010. We analyzed the differences between the experiments in capturing the surface pressure, wind speed, and roughness length. Both ERA5 reanalysis data and our regional model simulations demonstrate high quality in capturing wind and wave conditions over the ECS. The results show that downscaled simulations tend to be closer to in situ observations than ERA5 reanalysis data in capturing wind variability and probability distribution, dominant wind and wave directions, strong typhoon intensity and related extreme significant wave height. In comparison with satellite observations, the CCLM-WAM simulation outperforms the CCLM in reducing wind bias. The coupled and uncoupled simulations are very similar in terms of other wind and wave statistics. Though there is much improvement in capturing typhoon intensity to ERA5, regional downscaled simulations still underestimate the wind intensity of tropical cyclones.
\end{abstract}

Keywords: atmosphere-wave coupled model; East China Sea; wind; wave; tropical cyclones

\section{Introduction}

The interaction between different Earth system components, which include the sun, atmosphere, ocean, land, and ice, is non-linear and important for regional climate variations. Ocean surface wind waves are well known to affect the overlying atmosphere and play a dominant role in ocean-atmosphere interactions. Wind forces the generation of multiple oceanic phenomena, such as surface waves, storm surges, upwelling, and downwelling [1-5]. The wind is the dominant energy source for driving large-scale ocean circulations and maintaining abyssal stratification [6]. Wind waves greatly 
impact the atmosphere-ocean turbulence fluxes in heat, momentum, mass, and energy [7], which are also significantly influenced by wave-induced drag, swell propagation, and wave breaking $[8,9]$. The changes in the fluxes mediate the large-scale atmospheric circulation patterns, ocean states and climate. Furthermore, waves can impact the generation of currents via Stokes drift and induce upper ocean mixing through wave breaking.

Stand-alone atmospheric or ocean models have been used widely by the community for many years. However, uncoupled models feature some limitations, as they do not resolve air-sea interaction processes and regional feedbacks [10]. For standalone atmospheric modeling, many studies have shown that there are general overestimates for weak wind. In contrast, there are underestimates for strong wind, especially during typhoon or storm events [11,12]. With high spatial resolution, high-quality forcing datasets, or spectral nudging techniques, regional atmospheric modeling may improve the skills of simulating high-impact aspects of winds or mesoscale phenomena such as tropical cyclones [13] or coastal winds [14], which will further contribute to the improvement of forcing wave simulations [15-17]. However, large uncertainties in extreme wind modeling still exist [18], and these uncertainties are caused by an unrealistic description of physics in the modeling of these extreme events [19-22].

Wind stress parameterization (WSP) in atmospheric modeling is generally formulated by wind-dependent drag coefficients or roughness lengths, which fit only open ocean conditions. Edson et al. [23] indicated that surface roughness formulations that depend on wind speed and wave state give similar results over open water and wind conditions of $5-25 \mathrm{~m} / \mathrm{s}$. This result was found because of the linear variation in wave state with wind speeds under $25 \mathrm{~m} / \mathrm{s}$. For stronger winds or coastal water conditions, joint measurements show that WSP is greatly impacted by the sea surface wave state [24-26]. Drennan et al. [27] revealed that a wave steepness-based formulation (e.g., [28]) fits mixed sea conditions, while a wave age-based formulation (e.g., [29]) is more suitable for undeveloped young wind sea. Although many studies have shown the significance of wave-dependent physical processes in atmospheric/oceanic modeling, it was the establishment of coordinated ocean-wave climate projections (COWCLIP, [30]) that promoted the community interests in incorporating wave models in regional climate models, global climate models or physical coupled atmosphere-ocean models [7,20,21,31-37]. Fan et al. [33] developed a global high-resolution atmosphere-wave coupled model, which showed good agreement with observations in wave heights and some improvement to ERA40 in simulating significant wave heights. Shimura et al. [35] revealed that global climate simulations with wave-dependent roughness result in a $25 \%$ improvement in wind speed intensity in comparison with wind speed-dependent roughness. Additionally, it caused a significant change in atmospheric circulations. Larsén et al. [34] simulated 23 years of storms using the atmospheric Weather Research and Forecasting (WRF) model and spectral wave model for near shore (SWAN) coupled model through a wave boundary layer model (WBLM) implemented in SWAN, which handles the physics of the air-sea interface. Their results demonstrated that the coupled model through a WBLM matched better with observations than the uncoupled model, especially for extreme wind conditions. For the development of extratropical lows, momentum fluxes play an important role. If an atmospheric model is coupled to a wave model, the momentum flux is calculated as being dependent on sea-state and causes less deepening of the lows during model simulation [38,39]. In the case of hurricanes, however, the heat flux can also play a major role in the development of the low. Bao et al. [40] demonstrated that by coupling waves and atmosphere models, a hurricane can become deeper. Katsafados et al. [41] showed that feedbacks between the atmosphere and wind waves generate non-linear interactions within the dynamic structure of a storm or cyclone. Rizza et al. [22] revealed that the simulated skills of a Medicane track and intensity will be greatly improved if the wave-atmosphere model integrated impacts of wave state and sea spray on roughness length for momentum transport.

However, these studies mostly focus on the whole globe or marine areas, such as the North Sea and the Mediterranean Sea, while few studies have investigated the atmosphere-wave coupling and its influence on the East China Sea (ECS) with high-resolution modeling. The coastal regions 
of the ECS feature a very dense population and are greatly threatened by many natural hazards, such as tropical cyclones and extreme waves. It is of great significance to build a high-resolution atmosphere-wave coupled model for predicting accurate wind and wave conditions, especially for those during extreme events.

In this study, we aim to investigate the influence of high-resolution atmosphere-wave coupling in simulating the wind and wave fields over the ECS, and we focus on typhoon events. High-resolution stand-alone atmosphere and wave model simulations and coupled atmosphere-wave model runs were conducted and validated against both buoy/platform observations and satellite data in 2010 . Furthermore, the skills of the new ERA5 climate reanalysis dataset [42] from the European Centre for Medium-Range Weather Forecasts (ECMWF) were first assessed over the ECS in terms of both forcing atmosphere/wave regional models and generating wind and wave parameters, especially during typhoon events.

The paper is organized as follows: Section 2 introduces the models and simulations setups, datasets and methods, and sea surface roughness parameterization schemes. Sections 3 and 4 present the validation results of simulated winds and waves against station and satellite observations, respectively. Section 5 discusses the impact of atmosphere-wave coupling on means and extremes. The summary and conclusions are given in Section 6.

\section{Experimental Setup and Datasets}

\subsection{Model Description and Simulation Setups}

\subsubsection{Atmospheric Model-CCLM}

The non-hydrostatic regional climate model COSMO-CLM (CCLM, [43]) version 5.6 was used in this study. CCLM is the climate version of the operational weather forecast model COSMO, which was developed by the German Weather Service (DWD). The model is based on primitive thermo-hydrodynamic equations, which describe compressible non-hydrostatic flow in a moist atmosphere. The model equations are formulated in a rotated geographical coordinate system with a generalized terrain-following height coordinate [44]. The initial and boundary conditions (including sea surface temperature boundary forcing) of coupled and uncoupled CCLM model simulations are provided by the one-hourly ERA5 reanalysis dataset (see Table 1 for the list of experiments). A spectral nudging technique [45] was applied on the horizontal wind fields over $850 \mathrm{hPa}$ to ensure the model solution was consistent with the forcing at large scales. The model domain of CCLM in this study covers the East China Sea with a spatial resolution of $0.0625^{\circ}$, with $200 \times 316$ grid points in the longitudinal and latitudinal directions (Figure 1). There are 10 grid boxes setting as the sponge zone at each boundary and 40 layers in the vertical direction. The time step is $42 \mathrm{~s}$. The physical parameterizations used in the CCLM are similar to those described in Li et al. [46].

Table 1. Experiment setups.

\begin{tabular}{cccc}
\hline Exp. Name & Full Name & Variable for Comparison & Boundary Conditions \\
\hline CCLM & $\begin{array}{c}\text { standalone CCLM } \\
\text { simulation }\end{array}$ & $\begin{array}{c}\text { Wind speed (ws) and direction } \\
\text { (wdir) }\end{array}$ & ERA5 boundary data \\
\hline WAM_E & $\begin{array}{c}\text { standalone WAM simulation } \\
\text { driven by ERA5 winds }\end{array}$ & $\begin{array}{c}\text { Significant wave height (swh), } \\
\text { mean wave direction (mwd) }\end{array}$ & $\begin{array}{c}\text { ERA5 winds, } \\
\text { NW-Pacific WAM }\end{array}$ \\
\hline WAM_C & $\begin{array}{c}\text { standalone WAM simulation } \\
\text { driven by CCLM winds }\end{array}$ & swh, mwd & $\begin{array}{c}\text { CCLM winds, } \\
\text { NW-Pacific WAM }\end{array}$ \\
\hline CCLM-WAM & $\begin{array}{c}\text { Coupled CCLM-WAM } \\
\text { simulation }\end{array}$ & ws, wdir, swh, mwd & $\begin{array}{c}\text { ERA5 boundary data, } \\
\text { NW-Pacific WAM }\end{array}$ \\
\hline
\end{tabular}




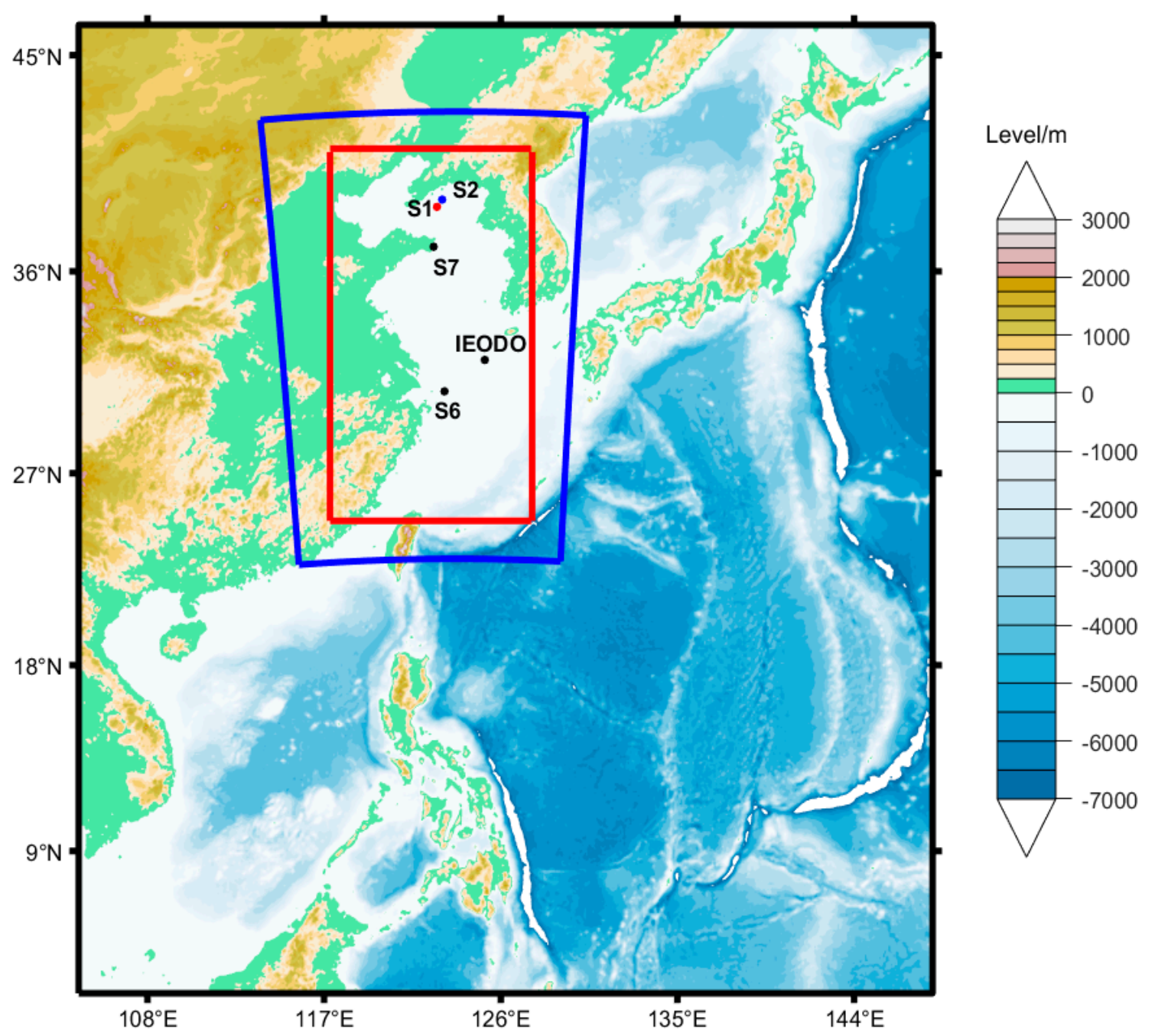

Figure 1. Topography of model areas: The outermost one indicates a domain for WAM simulation over the northwest Pacific region with a special resolution of $0.1^{\circ}$ (NW-Pacific WAM), red square indicates domain of fine-resolution $\left(0.05^{\circ}\right)$ WAM simulation and CCLM-WAM coupling, nested within NW-Pacific WAM, the blue square is the domain of CCLM simulations. Black points indicate the locations of wind and wave observations, red points represent the locations of wind observations only, and blue points represent the locations of wave observations only.

\subsubsection{Wave Model: WAM}

The third-generation WAM Cycle 4.6.5 [47] was used in this study. The wave spectrum is computed by the integration of the energy balance equation, without any prior restrictions on the evolution of the spectra [48]. The source function integration scheme was made by [49], and the updated source terms of [50] and IFS, Cycle 45R1, were incorporated. The model runs in a shallow wave mode, with depth refraction and wave breaking taken into consideration.

Open boundary data for the East China Sea domain were obtained by double-downscaling the wave model (i) a global $0.5^{\circ}$ model was established and downscaled to (ii) the Northwest Pacific Ocean configuration with a special resolution of $0.1^{\circ}$ (NW-Pacific WAM, see Figure 1) to (iii) the East China Sea setup with a spatial resolution of $0.05^{\circ}(207 \times 329$ model grid points). The wind forcing of WAM for the global and North Pacific configurations was taken from the ERA5 dataset. Two standalone WAM simulations for the East China Sea were performed in this study and forced by two different wind vectors: ERA5 winds (WAM_E) and standalone CCLM winds (WAM_C) (see Table 1 for the description of model experiments). The WAM model spectra are composed of 36 directions and 
30 frequencies, exponentially spaced and ranging from 0.04 to $0.66 \mathrm{~Hz}$. The topographic data used for wave simulations came from the General Bathymetric Chart of the Oceans one-minute grid data [51]. ERA5 monthly ice data were used as ice conditions for the wave model simulations.

\subsubsection{Coupling between CCLM and WAM}

In the fully two-way coupled model simulation (CCLM-WAM, see Table 1 and Figure S1), CCLM and WAM are coupled via the OASIS3-MCT, version 2 coupler [52], which exchanges the wind and sea surface roughness length between CCLM and WAM with a 6-min frequency. The wave model over the ECS is forced by the winds provided by the atmospheric model CCLM, while the sea surface roughness length of the atmospheric model is provided by the wave model through the OASIS3-MCT coupler. All experiments were performed for the year 2010, which is when several typhoons passed through the ECS and in situ observations were available for model skills assessment.

To assess the impact of coupling the wind wave model and the atmospheric model, the results between the coupled model simulations (CCLM-WAM) and the uncoupled simulations (CCLM and WAM_E and WAM_C) were compared. This process is illustrated through statistical analyses and differences between the coupled and uncoupled runs for the major parameters close to the surface (e.g., $10 \mathrm{~m}$ wind and significant wave height).

\subsection{Datasets and Methods}

To assess the role of the two-way coupling, the different experiments were compared with satellite and in situ model simulations. Below, we provide information about the different data used in this study.

\subsubsection{ERA5 Reanalysis}

ERA5 is the fifth major global reanalysis dataset developed by the ECMWFs using 4D-Var data assimilation in the CY41R2 ECMWFS' Earth System Model. It currently covers the period of 1979 to the present and will extend back to 1950 in 2020, with a horizontal resolution of $31 \mathrm{~km}$ globally, 139 vertical levels up to $0.01 \mathrm{hPa}$, and hourly output frequency. ERA5 generally outperforms ERA-Interim in the troposphere, e.g., through improved global hydrological and mass balances and a smaller precipitation bias [53]. Vast amounts of satellite and in situ observations have been assimilated in ERA5 reanalysis data, including wave height from the Jason- 1 and Jason-2 satellites and backscatter data (for deriving wind speeds) from ASCAT data, which was also used as a reference for model validation.

\subsubsection{In-situ Observations}

Observations were collected from four buoys and one platform (Figure 1) from the Marine Science Data Center (MSDC) of the Chinese Academy of Sciences and the National Oceanographic Data Center (NODC) of the US, respectively. The detailed information of each station observation is shown in Table 2 . The observed wind speeds at different heights were converted to the 10-m height, considering the wave dependence of the sea surface roughness length through the Charnock relation [54]. All buoy and platform observations in 2010 were used to validate the model outputs. For comparison, model grid data were interpolated to the stations' locations based on the nearest-neighbor method. All comparison results are for the year 2010.

\subsubsection{Satellite Data}

The Jason-1 and Jason-2 satellites were initiated to measure sea surface wind speed, wave height and sea surface height by the National Center for Space Studies and the National Aeronautics and Space Administration of the US for monitoring and forecasting ocean variations. The satellites were launched in 2001 and 2008, respectively. Their orbit coverage over the ECS is given in Figure S2. The wind or wave measurements of Jason- 1 and Jason- 2 nearest to the CCLM or WAM grid points 
and within $1 \mathrm{~h}$ from the simulated full hour were averaged and assigned as "observations" for the simulated CCLM or WAM grid. All simultaneous pairs were selected for the simulation validations.

The statistical metrics used for the comparison of simulated data with observations were the bias, mean absolute error (MAE), correlation coefficient (Corr), root mean square error (RMSE), normalized centered root mean square error (NCRMSE) and normalized standard deviation (NSD) [11]. The statistical significance of bias and mean absolute error between simulations and observations were determined by using Student's t-test. The 95\% confidence intervals were calculated to estimate their uncertainties.

\subsection{Sea Surface Roughness Length Parameterizations}

The roughness length over water directly influences the air-sea fluxes in heat, momentum, mass, and energy. For the standalone regional climate model CCLM, it was parameterized as a function of surface conditions varying with wind speed [55]. A modified Charnock formula is implemented as follows:

$$
z_{0}=\frac{\alpha}{g} \max \left(u_{*}^{2}, w_{*}^{2}\right)
$$

where the Charnock parameter is $\alpha=0.0123, u_{*}$ is the friction velocity, and $w_{*}$ is the free convection scaling velocity. For ice covering water surfaces, $z_{0}$ is set to $0.001 \mathrm{~m}$.

For the CCLM-WAM coupled model, the roughness length was expressed as a function of the wave-induced stress $\tau_{w}[56,57]$,

$$
z_{0}=\alpha_{1} \frac{u_{*}^{2}}{g} \frac{1}{\sqrt{1-\tau_{w} / \tau}}
$$

where $\alpha_{1}=0.006$, so that the Charnock parameter for old wind sea equals 0.0185 , which is consistent with observations [58]. $\tau$ is the total surface stress. The wave-induced stress $\tau_{w}$ represents the momentum fluxes transferred from the atmosphere to the waves, which can be related to the wind-wave growth and the directional wave spectrum.

Table 2. List of station observations at buoy station and platform. Observation parameters including wind speed (ws), wind direction (wdir), significant wave height (swh) and mean wave direction (mwd).

\begin{tabular}{ccccccc}
\hline Station & Lon & Lat & Parameters & Height (m) & Water Depth (m) & Type \\
\hline S1 & 122.75 & 38.76 & ws, wdir & 3 & 52 & buoy \\
\hline S2 & 123.013 & 39.067 & swh & 3 & 37.3 & buoy \\
\hline S6 & 123.135 & 30.715 & ws, wdir, swh & 10 & 61 & buoy \\
\hline S7 & 122.58 & 37.0625 & ws, wdir, swh & 3 & 30 & buoy \\
\hline IEODO & 125.184 & 32.12 & ws, wdir, swh, mwd & 43.5 & 41 & platform \\
\hline
\end{tabular}

\section{Validation}

\subsection{Model Assessment of $10 \mathrm{~m}$ Wind against Station Observations}

Taylor diagrams [59] (Figure 2) were used to demonstrate the comparisons of simulated wind against in situ observations for the four different stations (see Figure 1 and Table 1 for station locations). The results show that correlation coefficients between modeled and observed data are generally larger than 0.7 , and the ERA5 reanalysis data performed better. In the case of the normalized centered root mean square error, we found that the values were in the range of 0.5-1.0, with ERA5 having the smallest value. CCLM and CCLM-WAM are generally similar in terms of representing the observed wind speeds. They outperform ERA5 in capturing the standard variability of observations, with values around 1 at three stations. The statistical measures between simulations and four stations for different wind intensities are summarized in Table 3. All bias and MAE values, except ERA5 wind bias between $4-8 \mathrm{~m} / \mathrm{s}$, pass the significance test at a significance level of 0.05 . It shows that the bias is positive for 
wind speeds below $4 \mathrm{~m} / \mathrm{s}$ and tends to be negative for wind speeds larger than $4 \mathrm{~m} / \mathrm{s}$. The bias and root mean square error for simulated wind speeds between 4-12 are in general smaller than ones of low wind speeds $(<4 \mathrm{~m} / \mathrm{s})$ and of large wind speeds $(>12 \mathrm{~m} / \mathrm{s})$, indicating the outperformance in simulated moderate wind speeds. For model inter-comparison, CCLM-WAM performs the best for low wind speed $(<4 \mathrm{~m} / \mathrm{s})$, CCLM the best for strong wind speeds $(>12 \mathrm{~m} / \mathrm{s})$, and ERA5 the best for moderate wind speeds $(4-12 \mathrm{~m} / \mathrm{s})$. These results show the high quality of the ERA5 reanalysis data in capturing the observed wind speed in the ECS. The statistics also demonstrate that the regional model (that was run without data assimilation) performs well and hs an added value to ERA5 reanalysis in capturing wind variability and low wind speed or strong wind speed features.
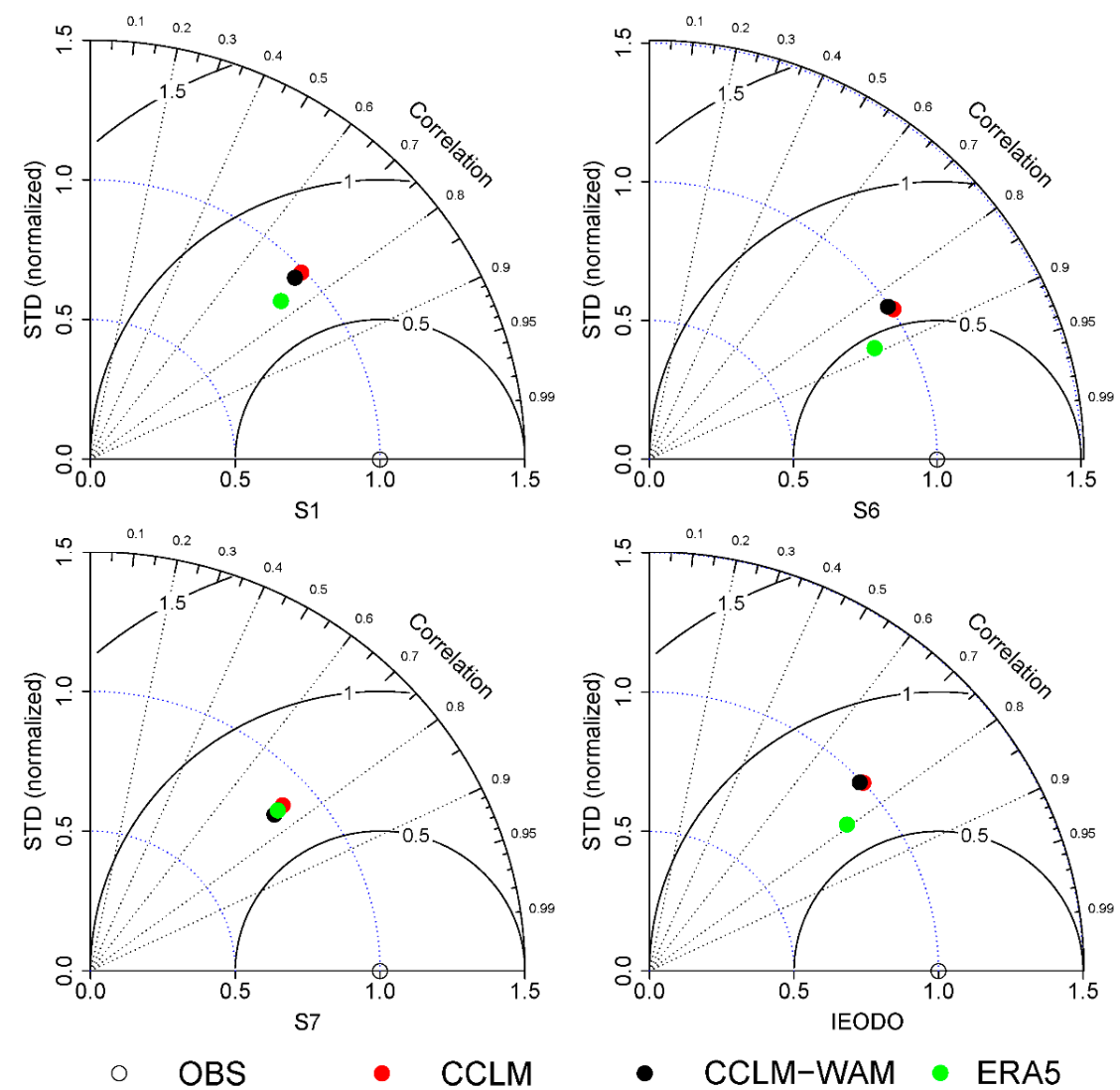

Figure 2. Taylor diagrams comparing the observations with three wind products for each station in 2010. The black contour lines represent the normalized centered root mean square errors, the blue contour lines represent the normalized standard deviations, and the azimuthal position of the point represents the correlation coefficient between the modeled and observed wind data.

Table 3. Bias (m/s), mean absolute error (MAE, $\mathrm{m} / \mathrm{s}$ ) and root mean square error (RMSE, $\mathrm{m} / \mathrm{s}$ ) for each range of wind speed between simulated results and observations. $95 \%$ confidence interval of bias and MAE are listed. Italic value means that it does not pass the significance test at a level of 0.05 . Bold represents the best skill in each column.

\begin{tabular}{|c|c|c|c|c|c|c|c|c|c|c|c|c|}
\hline \multirow{2}{*}{ Simulation } & \multicolumn{3}{|c|}{$<4 \mathrm{~m} / \mathrm{s}$} & \multicolumn{3}{|c|}{$4-8 \mathrm{~m} / \mathrm{s}$} & \multicolumn{3}{|c|}{$8-12 \mathrm{~m} / \mathrm{s}$} & \multicolumn{3}{|c|}{$>12 \mathrm{~m} / \mathrm{s}$} \\
\hline & BIAS & MAE & RMSE & BIAS & MAE & RMSE & BIAS & MAE & RMSE & BIAS & MAE & RMSE \\
\hline CCLM & $\begin{array}{c}1.16 \pm \\
0.10\end{array}$ & $\begin{array}{c}1.78 \pm \\
0.08\end{array}$ & 2.68 & $\begin{array}{c}-0.3 \pm \\
0.07\end{array}$ & $\begin{array}{c}1.58 \pm \\
0.05\end{array}$ & 2.04 & $\begin{array}{l}-0.78 \\
\pm 0.10\end{array}$ & $\begin{array}{c}1.66 \pm \\
0.07\end{array}$ & 2.24 & $\begin{array}{l}-1.33 \\
\pm 0.18\end{array}$ & $\begin{array}{c}1.76 \pm \\
0.15\end{array}$ & 2.71 \\
\hline CCLM-WAM & $\begin{array}{c}0.79 \pm \\
0.10\end{array}$ & $\begin{array}{c}1.66 \pm \\
0.08\end{array}$ & 2.50 & $\begin{array}{l}-0.67 \\
\pm 0.07\end{array}$ & $\begin{array}{c}1.74 \pm \\
0.05\end{array}$ & 2.18 & $\begin{array}{l}-1.11 \\
\pm 0.10\end{array}$ & $\begin{array}{c}1.68 \pm \\
0.08\end{array}$ & 2.31 & $\begin{array}{l}-2.04 \\
\pm 0.16\end{array}$ & $\begin{array}{c}2.18 \pm \\
0.15\end{array}$ & 3.04 \\
\hline ERA5 & $\begin{array}{c}1.56 \pm \\
0.10\end{array}$ & $\begin{array}{c}1.94 \pm \\
0.08\end{array}$ & 2.79 & $\begin{array}{c}0.13 \pm \\
0.06\end{array}$ & $\begin{array}{c}1.18 \pm \\
0.04\end{array}$ & 1.57 & $\begin{array}{c}-0.7 \pm \\
0.07\end{array}$ & $\begin{array}{c}1.19 \pm \\
0.05\end{array}$ & 1.61 & $\begin{array}{l}-1.81 \\
\pm 0.14\end{array}$ & $\begin{array}{c}1.88 \pm \\
0.13\end{array}$ & 2.73 \\
\hline
\end{tabular}


Figure 3 shows that the fitted Weibull distributions of the modeled wind data are consistent with one of the observed winds, at least for three out of four stations (exception of station S7). In terms of the modeled results, we found that the fitted Weibull probability distribution from the ERA5 winds underestimates the frequency of the observations at low wind speeds of less than $4 \mathrm{~m} / \mathrm{s}$, while it overestimates the frequency at medium wind speeds between 4 and $12 \mathrm{~m} / \mathrm{s}$. CCLM and CCLM-WAM both feature improvement over ERA5 in capturing wind speed probability distribution. However, the performance of CCLM and CCLM-WAM varies at different stations and wind intensities. At stations S1 and S6, CCLM is closer to the observations than CCLM-WAM, and the opposite occurs at station S7.
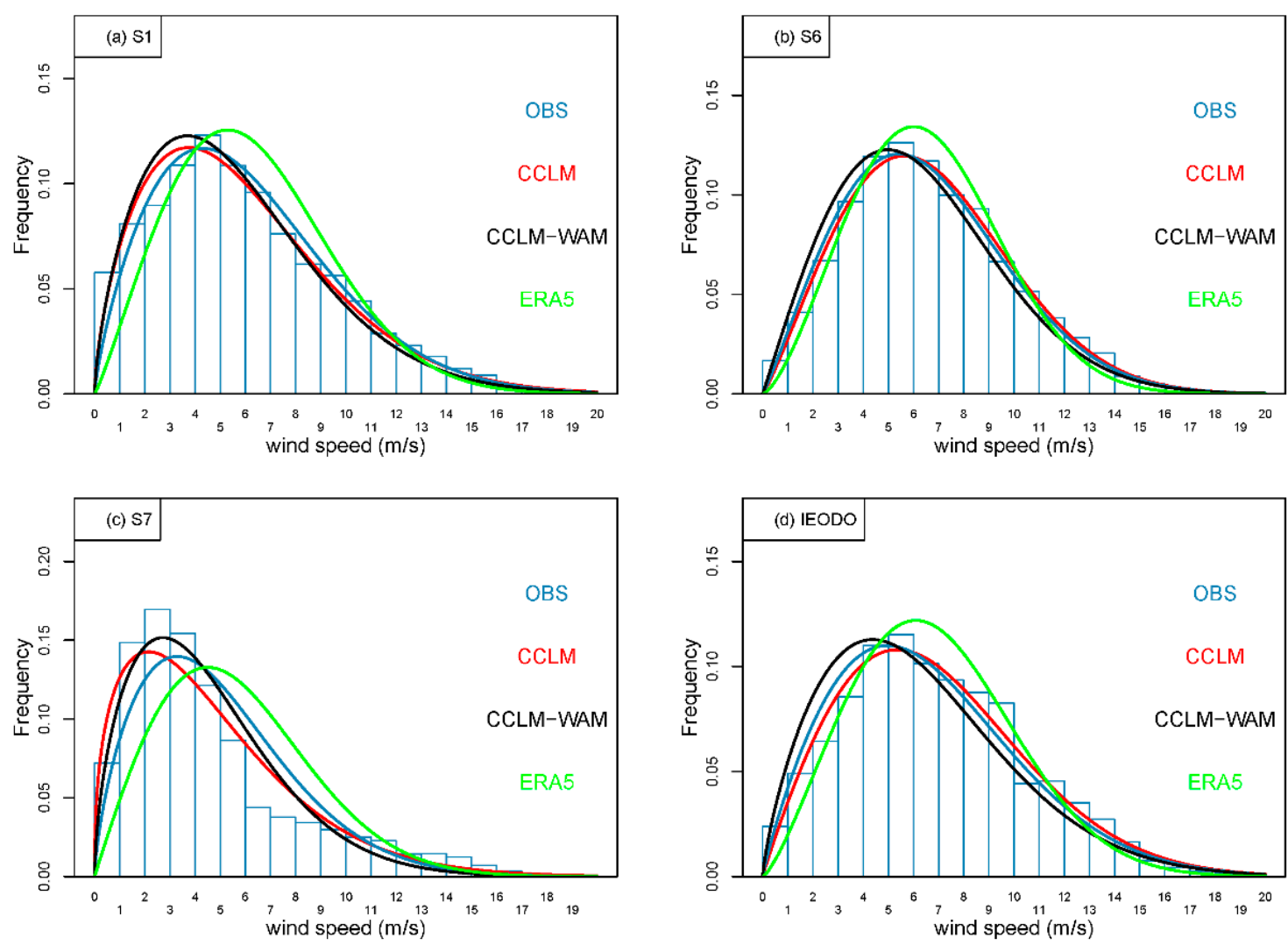

Figure 3. Observed wind histograms and fitted Weibull distributions for observed and simulated wind speeds at four stations in 2010.

The wind rose diagram at station IEODO (Figure 4) shows that the observed distribution patterns of wind direction can be realistically reproduced by all modeled results. The dominant winds are northerly and northeasterly winds, followed by southeasterly winds. The results of CCLM and CCLM-WAM are similar, and both feature some minor improvement relative to the ERA5 wind direction in comparison with observations. For near-coastal station S7, the wind direction is worse, especially for the ERA5 reanalysis data due to the coarse resolution. 


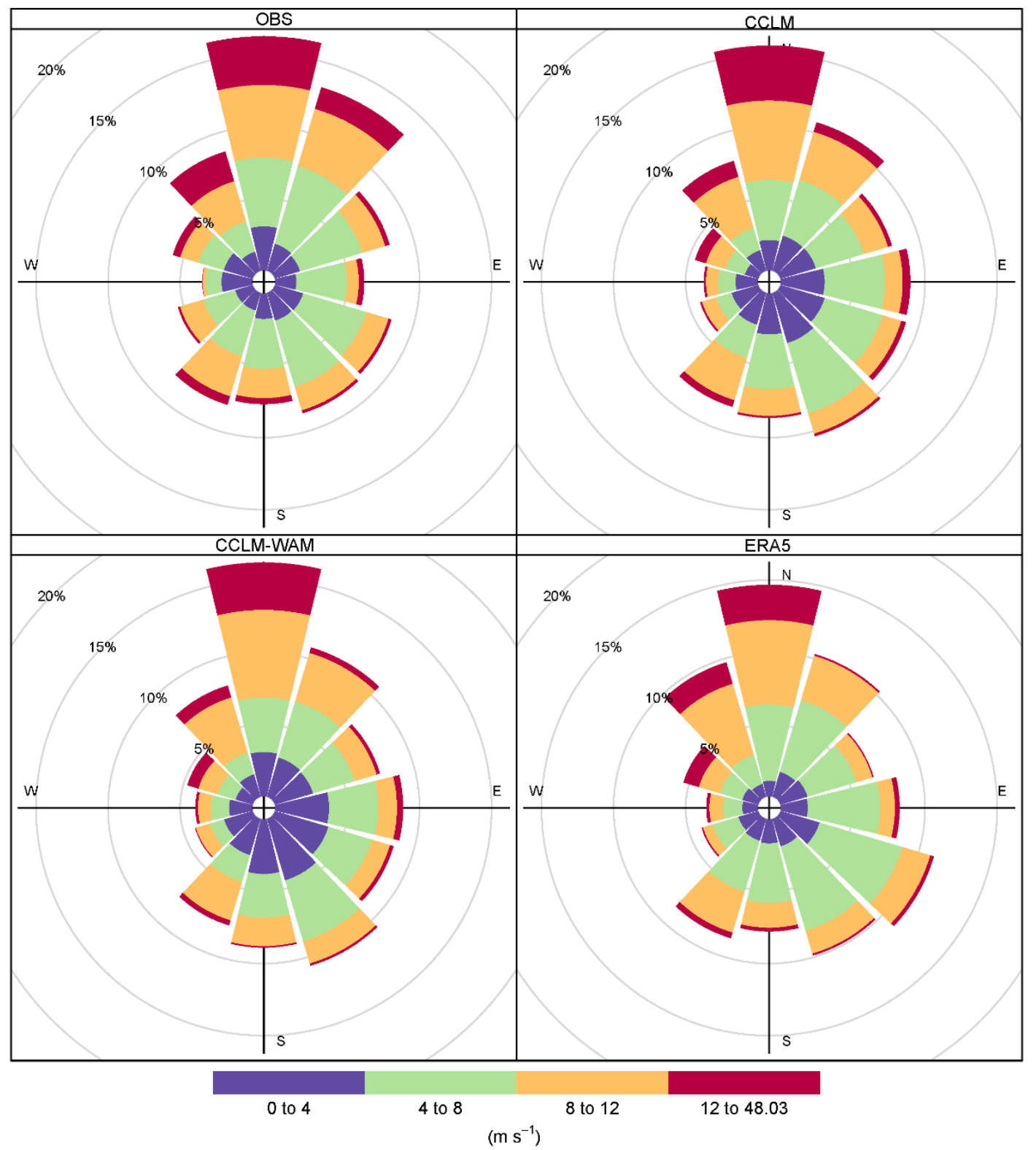

Figure 4. Wind rose diagrams at station IEODO for observations and modeled results. The wind direction interval is $30^{\circ}$.

\subsection{Model Assessment of Significant Wave Height against Station Observations}

For most of the stations (except S6) in Figure 5, the simulated significant wave height (SWH) is highly correlated with the observations, with values of approximately 0.9 (only S6 has a value below 0.8 ). The normalized centered root mean square errors are generally less than 0.5 , while the normalized standard deviations are close to 1 . All simulations generally have similar correlation coefficients. WAM_E and CCLM-WAM slightly outperform WAM_C and ERA5 when using the normalized centered root mean square error as a reference for stations S6 and S7.

The simulated SWH bias is generally small, with values less than $0.1 \mathrm{~m}$ except for station S6 (Table 4), and the BIAS differences between the experiments are minor. The MAE values are mostly in the range of $0.14-0.30 \mathrm{~m}$ and are smaller at stations S2 and S7 than at stations S6 and IEODO. Though bias and MAE values for simulated SWH are in general small, however, they mostly pass the significance test at a level of 0.05, except WAM_C simulation in SWH bias at station S7, indicating that they are significantly different from the observations. 

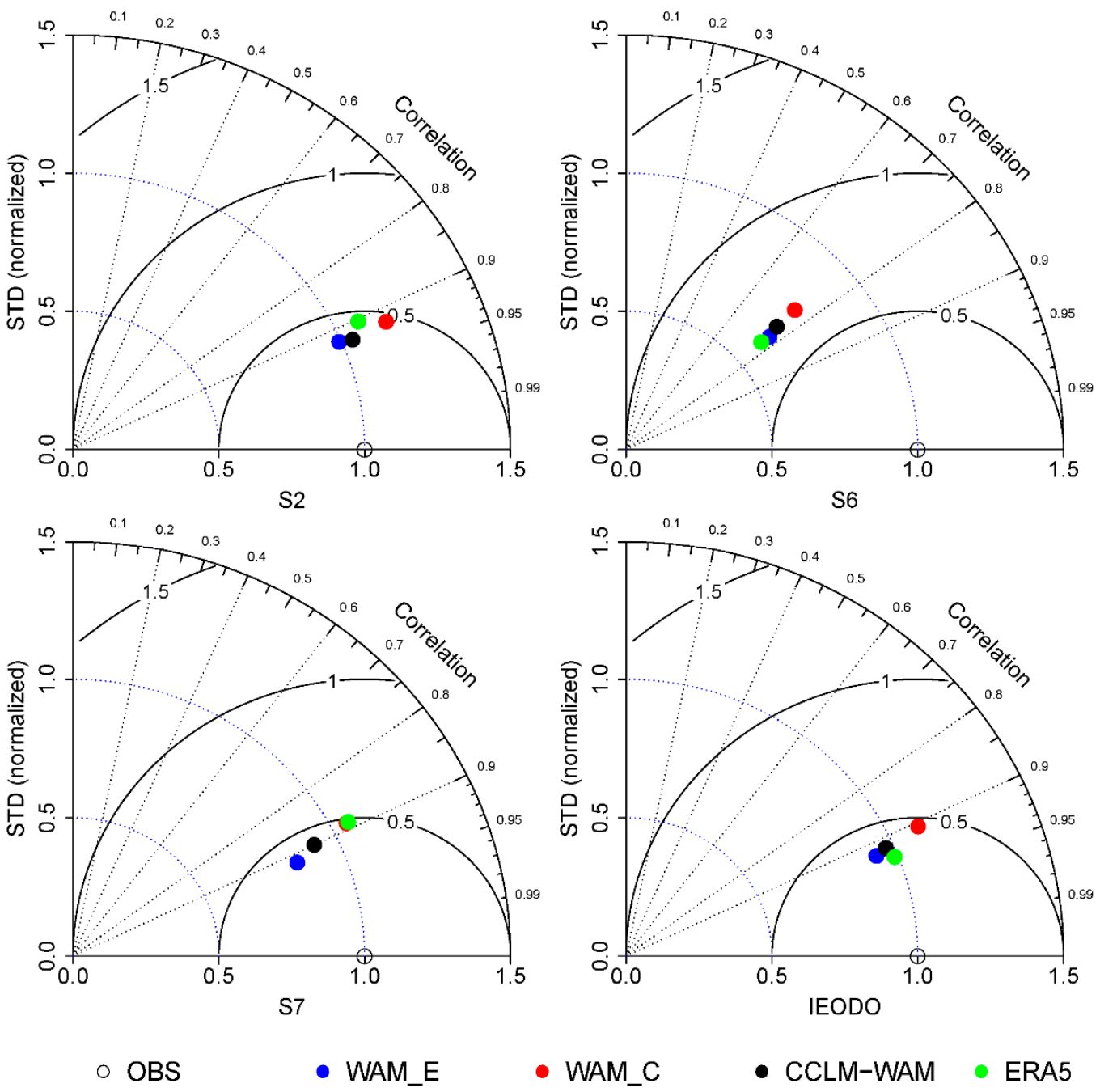

O OBS

- WAM_E

- WAM_C

Figure 5. The same as Figure 2 but for significant wave height at different stations.

Table 4. Bias (m) and mean absolute error (MAE, $\mathrm{m}$ ) between simulated and observed significant wave height at four stations. 95\% confidence interval of bias and MAE are listed. Italic value means that it does not pass the significance test at a level of 0.05 . Bold represents the best skill in each column.

\begin{tabular}{ccccccccc}
\hline \multirow{2}{*}{ Exp. } & \multicolumn{2}{c}{ S2 } & \multicolumn{2}{c}{ S6 } & \multicolumn{2}{c}{ S7 } & \multicolumn{2}{c}{ IEODO } \\
\cline { 2 - 9 } & $\begin{array}{c}\text { BIAS } \\
(\mathbf{m})\end{array}$ & $\begin{array}{c}\text { MAE } \\
(\mathbf{m})\end{array}$ & $\begin{array}{c}\text { BIAS } \\
(\mathbf{m})\end{array}$ & $\begin{array}{c}\text { MAE } \\
(\mathbf{m})\end{array}$ & $\begin{array}{c}\text { BIAS } \\
(\mathbf{m})\end{array}$ & $\begin{array}{c}\text { MAE } \\
(\mathbf{m})\end{array}$ & $\begin{array}{c}\text { BIAS } \\
(\mathbf{m})\end{array}$ & $\begin{array}{c}\text { MAE } \\
(\mathbf{m})\end{array}$ \\
\hline \multirow{2}{*}{ WAM_E } & $\mathbf{0 . 0 1}$ & $\mathbf{0 . 1 4}$ & -0.20 & 0.28 & -0.05 & $\mathbf{0 . 1 5}$ & $\mathbf{- 0 . 0 1}$ & 0.25 \\
& $\mathbf{0 . 0 0 4}$ & $\mathbf{\pm 0 . 0 0 3}$ & \pm 0.013 & \pm 0.012 & \pm 0.006 & $\mathbf{\pm 0 . 0 0 5}$ & $\mathbf{\pm 0 . 0 0 8}$ & \pm 0.005 \\
\hline \multirow{2}{*}{ WAM_C } & 0.04 & 0.16 & $\mathbf{- 0 . 1 4}$ & $\mathbf{0 . 2 7}$ & 0.01 & 0.16 & 0.07 & 0.28 \\
& \pm 0.005 & \pm 0.003 & $\mathbf{\pm 0 . 0 1 3}$ & $\pm \mathbf{0 . 0 1 2}$ & \pm 0.008 & \pm 0.006 & \pm 0.009 & \pm 0.007 \\
\hline \multirow{2}{*}{ CCLM-WAM } & -0.02 & $\mathbf{0 . 1 4}$ & -0.21 & 0.29 & -0.04 & 0.16 & $\mathbf{- 0 . 0 1}$ & 0.25 \\
& \pm 0.004 & $\pm \mathbf{0 . 0 0 3}$ & \pm 0.013 & \pm 0.012 & \pm 0.007 & \pm 0.005 & \pm 0.008 & \pm 0.005 \\
\hline \multirow{2}{*}{ ERA5 } & 0.03 & 0.16 & -0.32 & 0.35 & 0.07 & 0.17 & 0.04 & $\mathbf{0 . 2 4}$ \\
& \pm 0.005 & \pm 0.003 & \pm 0.013 & \pm 0.012 & \pm 0.008 & \pm 0.006 & \pm 0.007 & $\pm \mathbf{0 . 0 0 5}$ \\
\hline
\end{tabular}

Figure 6 shows that the patterns of the simulated mean wave direction are generally consistent with the observations at station IEODO. The dominant directions are northerly, southerly, and southeasterly, which are consistent with the directions of the measured wind speed at station IEODO. This result implies that larger parts of waves are contributed from the wind sea instead of the swell waves. ERA5 performs the worst among all simulations in capturing the mean wave direction patterns, 
while the high-resolution WAM simulations are consistent with each other in terms of representing the observed mean wave directions. Comparing WAM_C and CCLM-WAM with IEODO data, it is notable that in small wave ranges (up to $0.8 \mathrm{~m}$, the blue color), the two-way coupled run is becoming closer to the observation. It is also notable that CCLM-WAM performs best for the distribution of northerly waves.

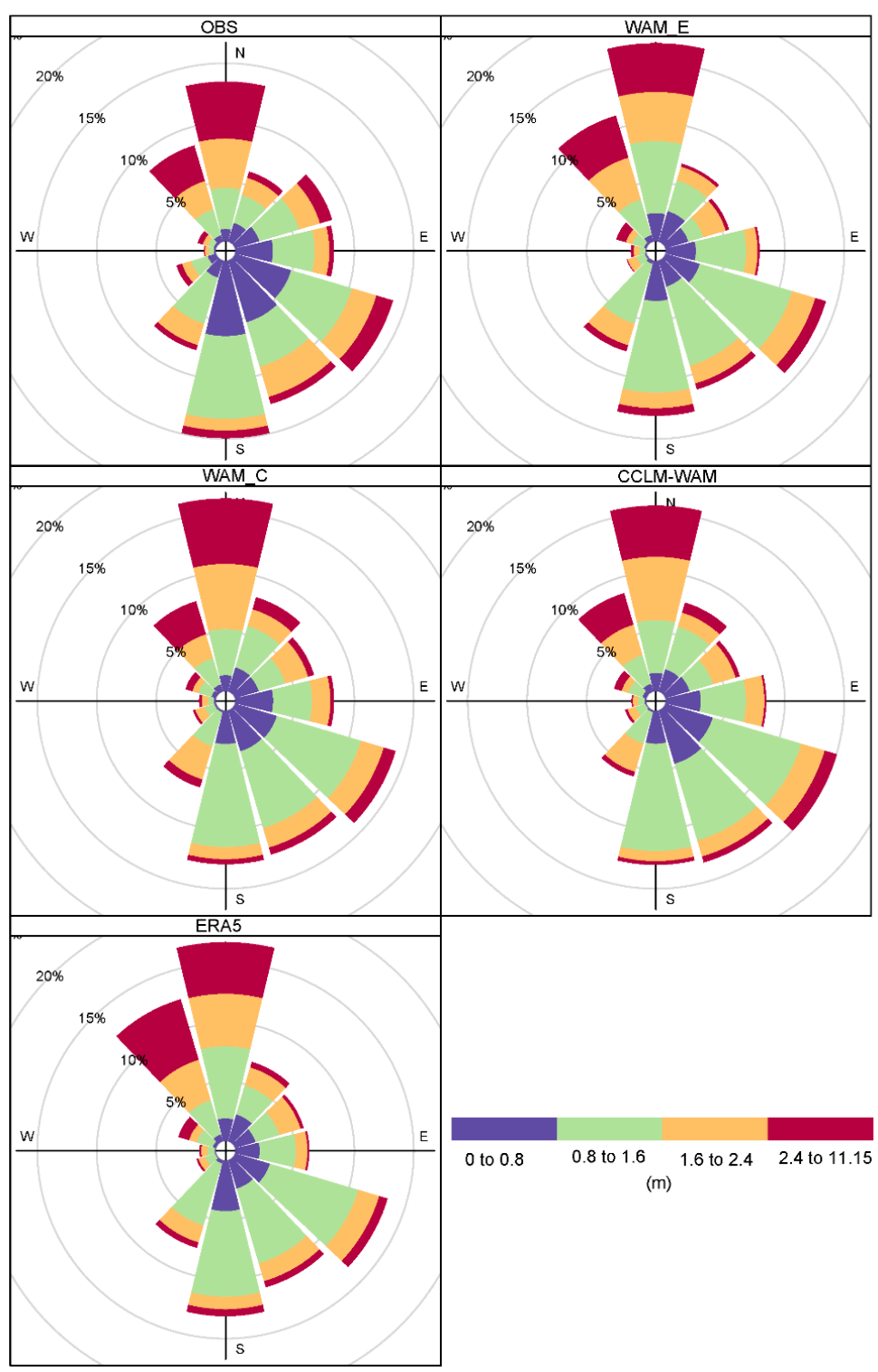

Figure 6. The same as Figure 4 but for the mean wave direction at station IEODO.

\subsection{Validation against Satellite Observations}

The results in the previous sections showed assessments against in situ observations. However, for our study area, such data are rare. Thus, for more comprehensive validation, Jason- 1 and Jason-2 satellite data were used to assess the capacity of the different simulations in capturing wind and wavefields over the ECS. Figure 7 reveals that the simulated bias is smallest for CCLM-WAM wind speeds (Jason-1: $-0.05 \mathrm{~m} / \mathrm{s}$, Jason-2: $0.02 \mathrm{~m} / \mathrm{s}$ ) and largest for ERA5 wind speeds (Jason-1: $0.31 \mathrm{~m} / \mathrm{s}$, Jason-2: $0.39 \mathrm{~m} / \mathrm{s}$ ). The normalized standard deviations of CCLM and CCLM-WAM wind are in the range of 1.01-1.05, being closer to the satellite observations than ERA5, which is consistent with results using station observations as a reference. If we use the Jason- 1 wind speed as a reference, 
all simulations are similar in terms of the MAE $(1.15 \mathrm{~m} / \mathrm{s}-1.17 \mathrm{~m} / \mathrm{s})$, CORR (0.89-0.90) and RMSE $(1.5 \mathrm{~m} / \mathrm{s})$, while ERA5 is slightly better than CCLM and CCLM-WAM if the Jason-2 wind speed is used as a reference. In terms of quantile-quantile plots, CCLM features the best performance, while CCLM-WAM and ERA5 generally underestimate strong wind speeds over $12 \mathrm{~m} / \mathrm{s}$. This result is due to the non-linear effects between the interaction of the atmosphere and the waves and the increased surface roughness leading to decreasing significant wave height at strong winds.
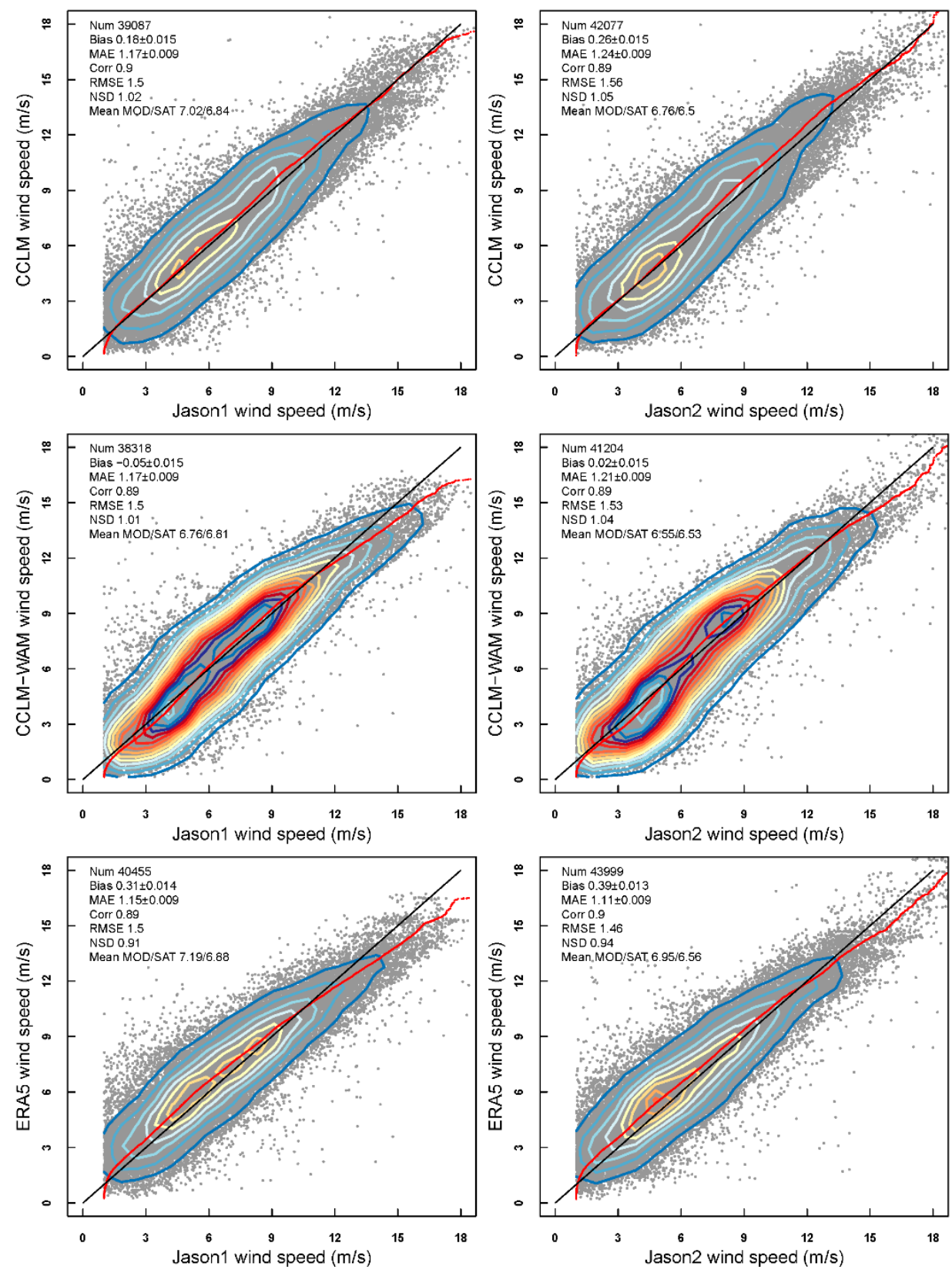

Figure 7. Comparison of modeled wind speed (y-axis) with Jason-1 (left column) and Jason-2 (right column) satellite wind observations (x-axis): Scatter plots (grey dots), qq plots (red dots), and several statistical measures (valid numbers of observations, bias, mean absolute error (MAE), correlation (Corr), root-mean-square error (RMSE), mean and normalized standard deviation (SD)). The kernel density estimations (contour lines) are included. Furthermore, 95\% confidence interval of bias and MAE are listed. 
Figure 8 shows that for the significant wave height, WAM_C is the best in terms of the normalized standard deviation (Jason-1: 0.99, Jason-2: 1.02). WAM_E, WAM_C, and CCLM-WAM are generally consistent with each other in terms of the other measures, such as MAE (0.25-0.27 m), Corr (0.92-0.93) and RMSE (0.33-0.35 m). ERA5 performs slightly better in most statistical measures except for the normalized standard deviation (Jason-1: 0.93, Jason-2: 0.96).
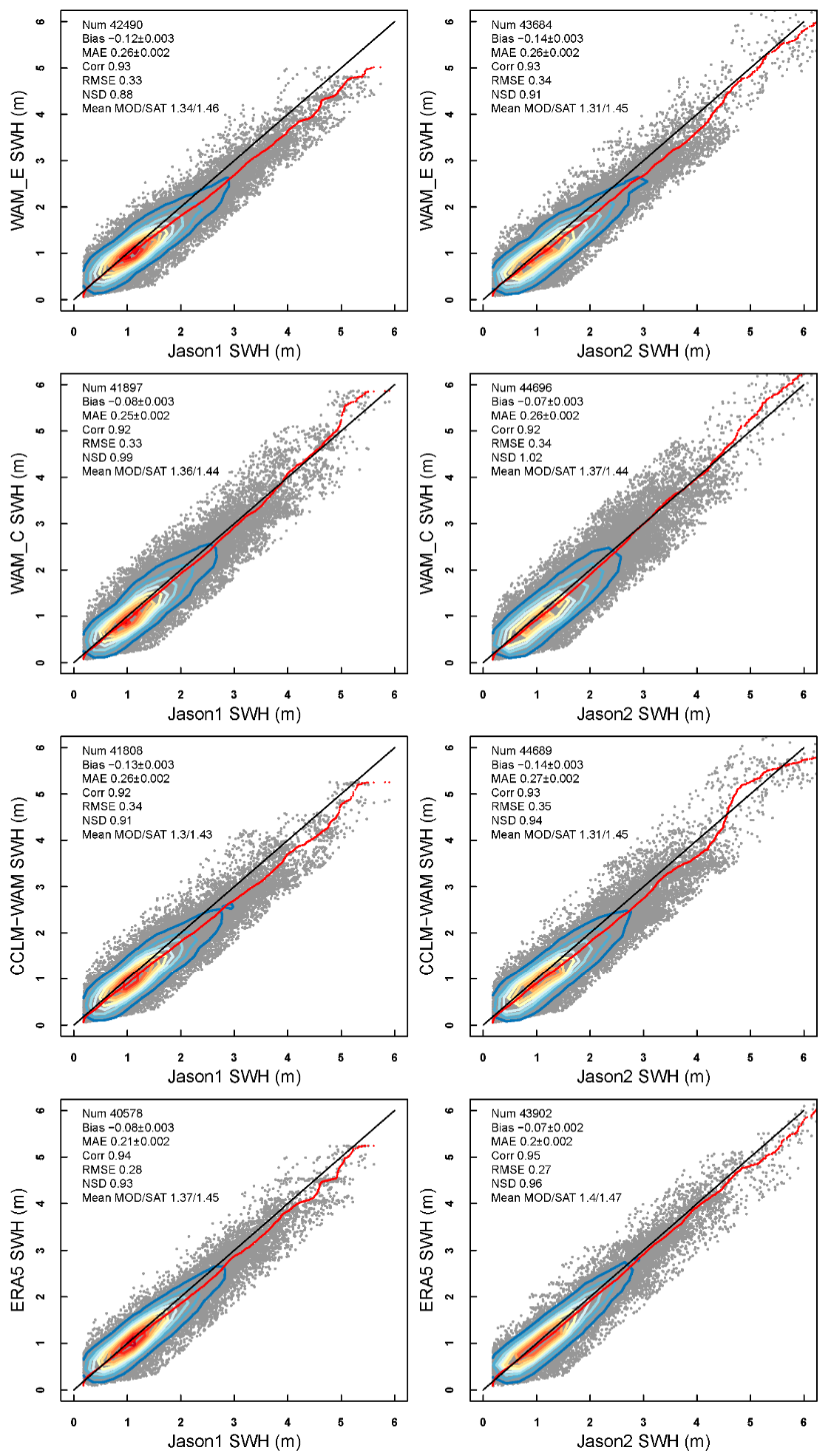

Figure 8. The same as Figure 7, but for significant wave height (SWH). 


\section{Typhoon Events}

In the following section, the model skills in terms of simulating a typhoon track and intensity will be demonstrated. The typhoon Kompasu is used as an example, and this typhoon passed through the ECS from 31 August and 02 September 2010 [60]. A tracking algorithm [13] was adopted to track this typhoon by searching for the maximum wind speed and minimum sea-level pressure within a distance around the track.

All simulated tracks of typhoon Kompasu are comparable in capturing the track of typhoon Kompasu (Figure 9). They are very similar to the track of the best track data from the Japan Meteorological Agency (JBTD) [61] and China Meteorological Agency (CBTD) [62]. In order to quantify the skills of simulated tracks, the great circle distances between JBTD and extracted tracks of model simulations, as well as CBTD, were calculated based on Haversine formula [63]. The great circle distances of simulated tracks are similar (with values 30-95 km) at the beginning when the simulated deviations from observations are larger than those during the evolution period. ERA5, in general, shows smaller deviations than downscaling simulations, which was consistent with the study by Feser and von Storch [64]. CCLM and CCLM-WAM share almost the same values in the great circle distances, which is in the range of 10-100 km. The atmosphere model experiments that we used underestimate the intensities of typhoon Kompasu: The observed minimum sea-level pressure is overestimated by $10-40 \mathrm{hPa}$, while the maximum $10-\mathrm{m}$ wind speed is underestimated by $4-20 \mathrm{~m} / \mathrm{s}$. The maximum wind speed of the re-analysis data of ERA5 used to force the CCLM and CCLM-WAM models showed the largest underestimation from the observations, which can be more than $20 \mathrm{~m} / \mathrm{s}$. It can be seen that the regional CCLM model and the CCLM-WAM performs better than ERA5 in capturing sea level pressure during 01 September 2010 and maximum 10-m wind speed for all tracked times. The improvement in wind speed intensities reaches up to $10 \mathrm{~m} / \mathrm{s}$ by downscaling. CCLM and CCLM-WAM are similar in reflecting minimum sea level pressure, while CCLM is closer than CCLM-WAM to the best track data in capturing the maximum 10-m wind speed over the coupled region when the typhoon intensities are underestimated by the simulations. However, the regional model domain of CCLM is too small to generate high typhoon intensity if the forcing data are strongly underestimated. Additional parameterizations (e.g., [23]) might be considered in this case, which will be discussed in the next section. It should be noted that the typhoon intensities between both observation datasets can be very large, especially during extreme wind conditions. Nevertheless, the observation uncertainties in typhoon intensities would not change the concluding results of this study.

The validation of simulated time series of wind speed and SWH against observations at stations IEODO and S6 during three typhoon events that occurred consecutively from the end of August to the middle of September is shown in Figures 10 and 11, respectively. At the IEODO station, for calm conditions (after 07 September 2019), all model data are very close to the observations. ERA5 performs worst at extreme wind speeds on approximately 01 September 2010 (with underestimation about $10 \mathrm{~m} / \mathrm{s}$ ) and best for wind speeds at other wind conditions. The wind intensity of the CCLM simulation is higher than that of CCLM-WAM at most times. For SWH, CCLM-WAM is better than WAM_C in capturing extreme waves around 01 and 05 September 2010. For the observed SWH with approximately $2 \mathrm{~m}$ intensity, all simulations are similar. 

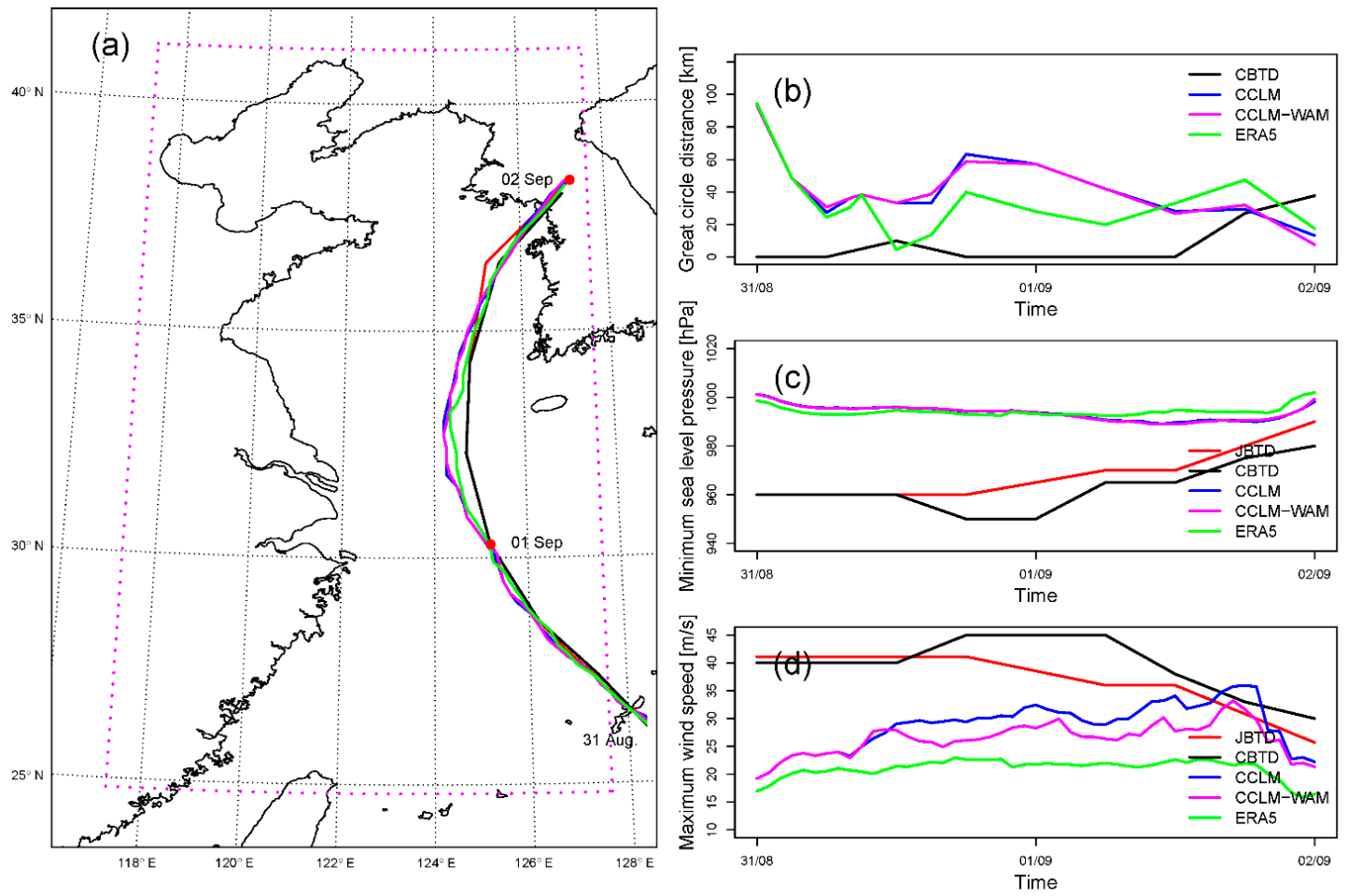

Figure 9. (a) Tracks of typhoon Kompasu from Best Track Data of Japan Meteorological Agency (red line, JBTD) and China Meteorological Agency (black line, CBTD), and corresponding model results, time series of (b) great circle distance between model simulations (CBTD) and JBTD, (c) the minimum sea-level pressure and (d) maximum 10-m wind speed. Magenta points in (a) indicate the domain of standalone WAM simulation/coupling simulation.
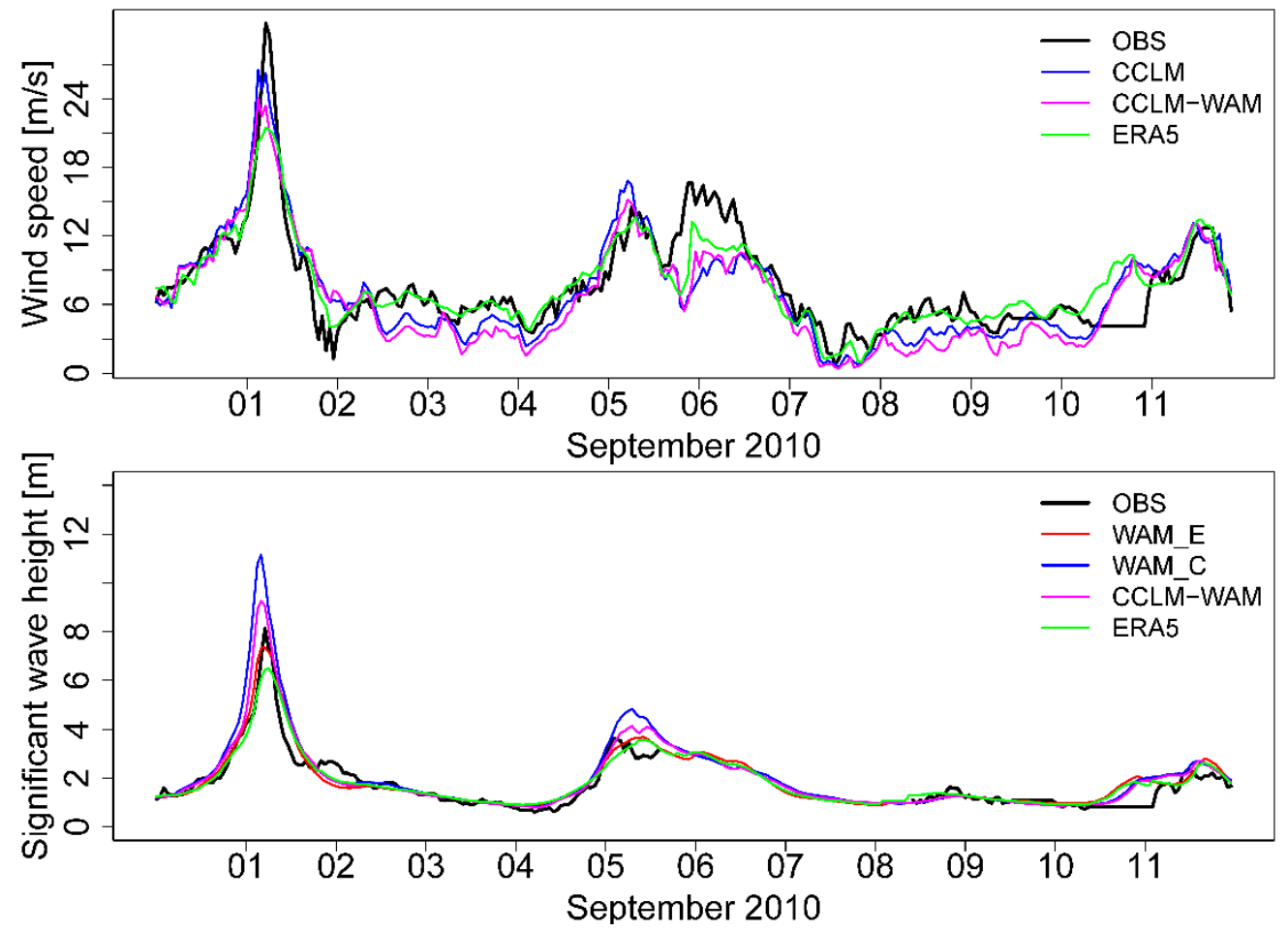

Figure 10. Wind speed and significant wave heights during three typhoon events at station IEODO. 

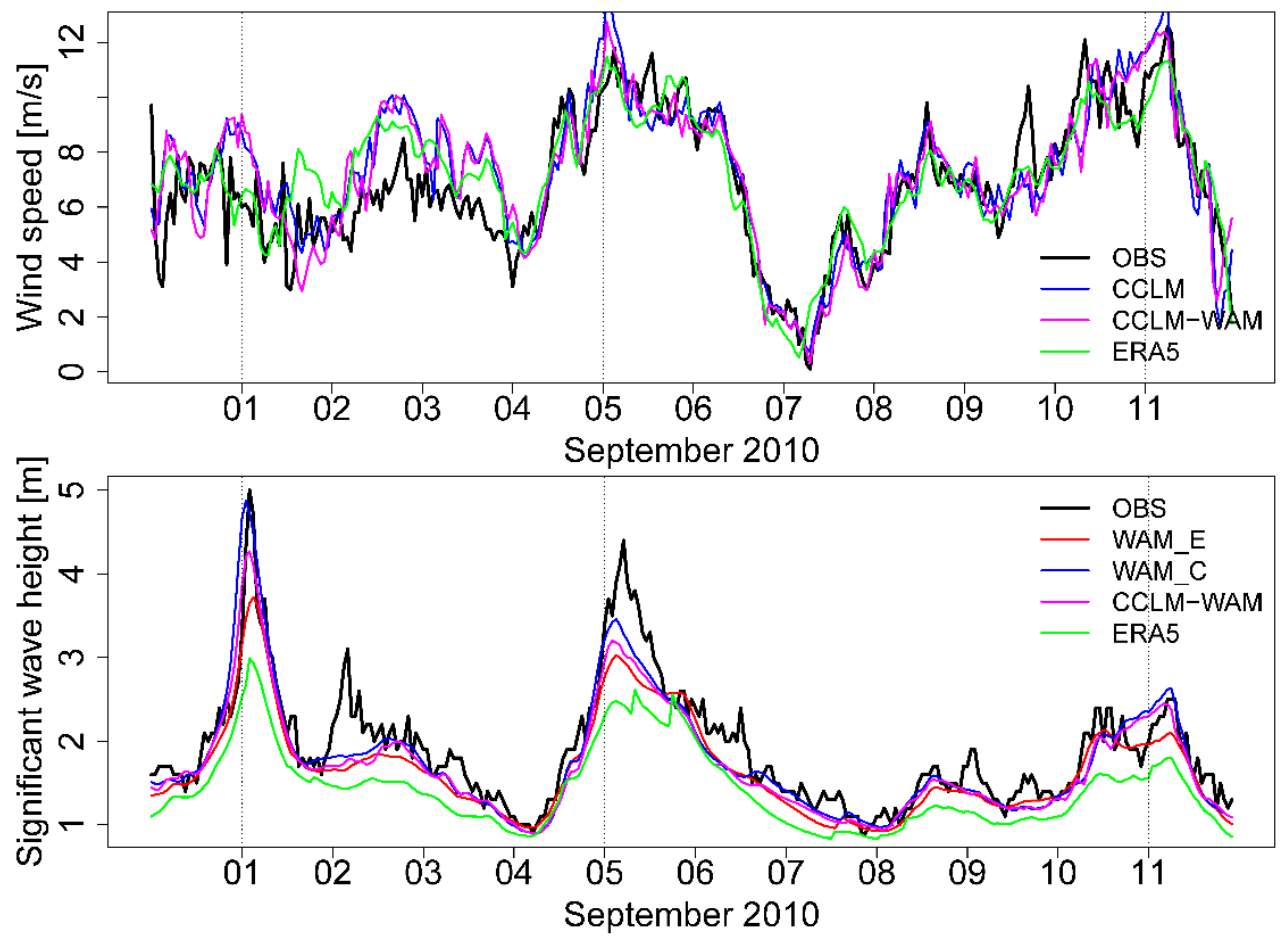

Figure 11. The same as Figure 10 but at station S6.

Figure 11 shows that the intensities of the wind speed and SWH at station $\mathrm{S} 6$ are much smaller than those at station IEODO. CCLM and CCLM-WAM simulations are generally similar in capturing wind speed intensities, while ERA5 is slightly better in capturing wind intensities at some times. For SWH, ERA5 performs the worst and its underestimation can be up to $3 \mathrm{~m}$. WAM_C is the best for extreme events. WAM_E, WAM_C, and CCLM-WAM are similar in relation to the other wave conditions.

Above all, it can be seen that the ERA5 reanalysis dataset is generally of high quality in reproducing observed wind speed and SWH. However, it shows low skill in capturing wind intensities of strong typhoon events, which can be better captured by downscaling simulations. Nevertheless, high-resolution uncoupled or coupled atmosphere waves still greatly underestimate the extreme wind speeds related to strong typhoons. The regional model area is too small and is critically dependent on the external forcing data. If the ERA5 data strongly underestimate the intensity of the typhoon, the regional model will be incapable of generating such strong wind. In addition, slightly better wind forcing does not guarantee better wave modeling at local scales because, except for wind seas, swells that propagate from far fields will also determine the local wave conditions.

\section{Impact of Coupling on Mean and Extremes}

As discussed in Section 2, the parameterization of the sea surface roughness length for the standalone CCLM simulation is wind-dependent, while it is wave-stress dependent for the coupled CCLM-WAM simulation. Figure 12 shows the relationships of the 10-m wind speed and roughness length estimated from the uncoupled CCLM and the coupled CCLM. For the coupled CCLM-WAM, the roughness length varies with wave age conditions under certain wind speeds. The fitted roughness length values of CCLM-WAM (blue line) are generally consistent with the CCLM parameterization for old sea states and wind speeds less than $8 \mathrm{~m} / \mathrm{s}$. However, it is much higher for young sea states and wind speeds greater than $10 \mathrm{~m} / \mathrm{s}$. In the parameterizations used in this study [57], the roughness length increases with wind speed. Furthermore, it is found that the acceleration of roughness length of CCLM-WAM is larger for strong winds than for weak winds. The relationship pattern of friction velocity and roughness length is very similar to that of $10-\mathrm{m}$ wind speed and roughness length. Consequently, both roughness length 
parameterizations will result in different relationships between wind speed/friction velocity and roughness length. The exchange of winds and roughness length between CCLM and WAM for coupled simulations will greatly and non-linearly impact the atmosphere and wave fields.

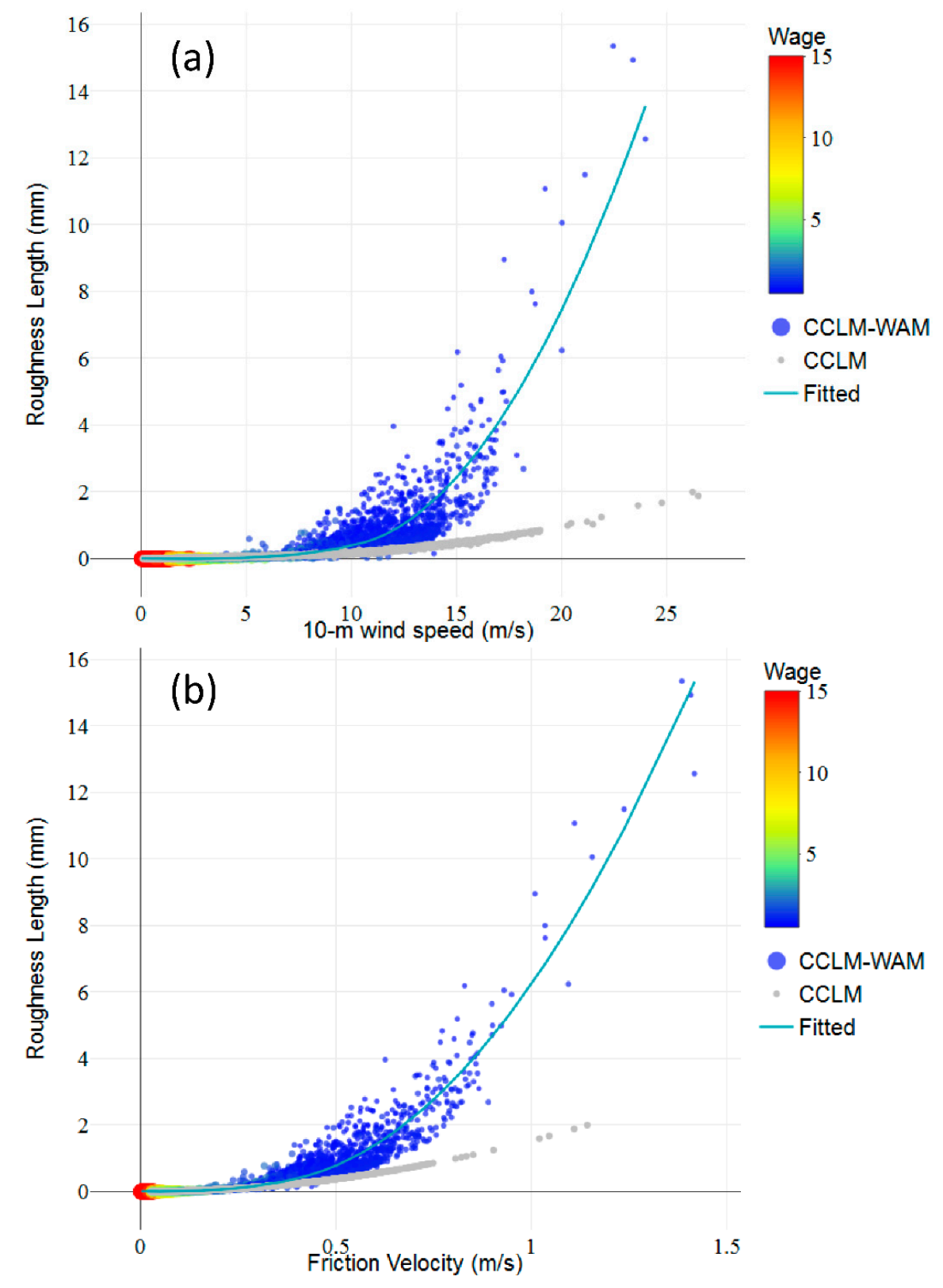

Figure 12. Relationship between (a) 10-m wind speed and roughness length, (b) friction velocity and roughness length at station IEODO for the year 2010. Colored points indicate the CCLM-WAM simulation, while grey points indicate the CCLM standalone simulation. The lines indicate the polynomial regression fitting lines for coupled simulations.

Figure 13a shows that the annual mean roughness length for the uncoupled CCLM simulation features small values that are generally less than $0.2 \mathrm{~mm}$. In contrast, the roughness lengths for the coupled CCLM-WAM simulation (Figure 13b) are mostly greater than $0.2 \mathrm{~mm}$. In the open area, the roughness length for the coupled CCLM-WAM simulation exceeds that of the uncoupled CCLM by $0-0.2 \mathrm{~mm}$, while the differences in some coastal areas are larger (Figure 13c), which leads to negative biases of the wind speed of the coupled CCLM-WAM against the uncoupled CCLM winds over the entire ECS (Figure 13f). The absolute wind speed differences are smaller in the offshore areas, especially 
in the southeastern part of the model domain, and are larger in the Bohai Sea and Taiwan Strait areas. Though differences exist, the annual mean spatial patterns for the annual mean wind speed between the coupled and uncoupled simulations look quite similar (Figure 13d,e). The wind speeds are generally in the range of $5-8 \mathrm{~m} / \mathrm{s}$, increasing from northwest to southeast. In the case of $\mathrm{SWH}$, the spatial patterns between the coupled and uncoupled simulations are also similar (Figure 13g,h). Consequently, the SWH is generally smaller than $0.9 \mathrm{~m}$ in the near-coastal areas and are in the range of 0.9-1.8 $\mathrm{m}$ for the offshore areas. The annual mean SWH for the coupled CCLM-WAM simulation is 0.04-0.12 m smaller than that for the uncoupled simulation (Figure 13i). Above all, we can see that the coupled model simulation with a sea state-dependent $\mathrm{Z} 0$ results in a smaller annual mean wind speed and SWH than the uncoupled model simulations with a wind-dependent Z0, which is supposed to be applicable for the climatological mean of long-term simulations.

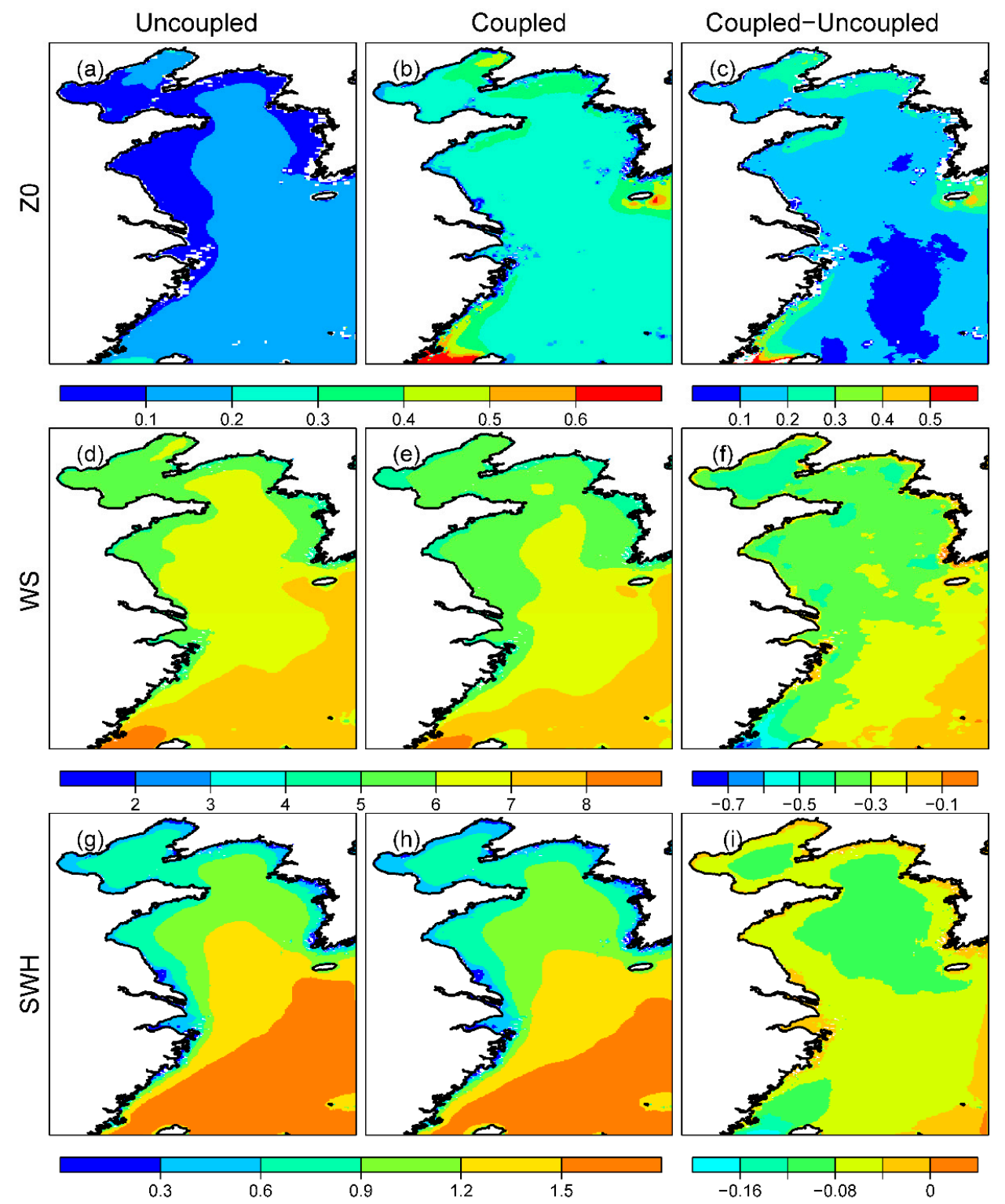

Figure 13. Annual mean roughness length ( $\mathrm{Z0}, \mathbf{a}, \mathbf{b}$, unit: $\mathrm{mm})$, wind speed (WS, d-e, unit: $\mathrm{m} / \mathrm{s})$ and significant wave height ( $\mathrm{SWH}, \mathbf{g}, \mathbf{h}$, unit: $\mathrm{m}$ ) for uncoupled and coupled simulations in 2010 and the differences between coupled and uncoupled simulations $(\mathbf{c}, \mathbf{f}, \mathbf{i})$. Here, uncoupled represents CCLM for WS and WAM_C for SWH, coupled represents CCLM-WAM for WS and SWH. 
In the previous sections, we investigated the skills of the ERA5, coupled and uncoupled simulations in capturing intensities and the track of the strong typhoon Kompasu by comparing the results with observations. Here, we further show the simulated spatial fields of the atmospheric and wave fields for typhoon Kompasu at 05:00 UTC, 01 September 2010 (Figure 14). In general, the spatial patterns look similar among the ERA5, uncoupled and coupled simulations in terms of wind speed/vectors, mean sea level pressure, significant wave height and peak wave period, with the latter two simulations being in better agreement with each other. However, differences exist due to the resolution or coupling setups, especially in the near-coastal areas. The coarse-resolution ERA5 reanalysis data feature relatively weaker intensities of typhoons and typhoon generated wind-waves in comparison with the high-resolution coupled or uncoupled simulations. The wind speeds and significant wave heights of the coupled simulation were smaller than those of the uncoupled simulations, which was caused by the larger roughness length for the coupled simulation.
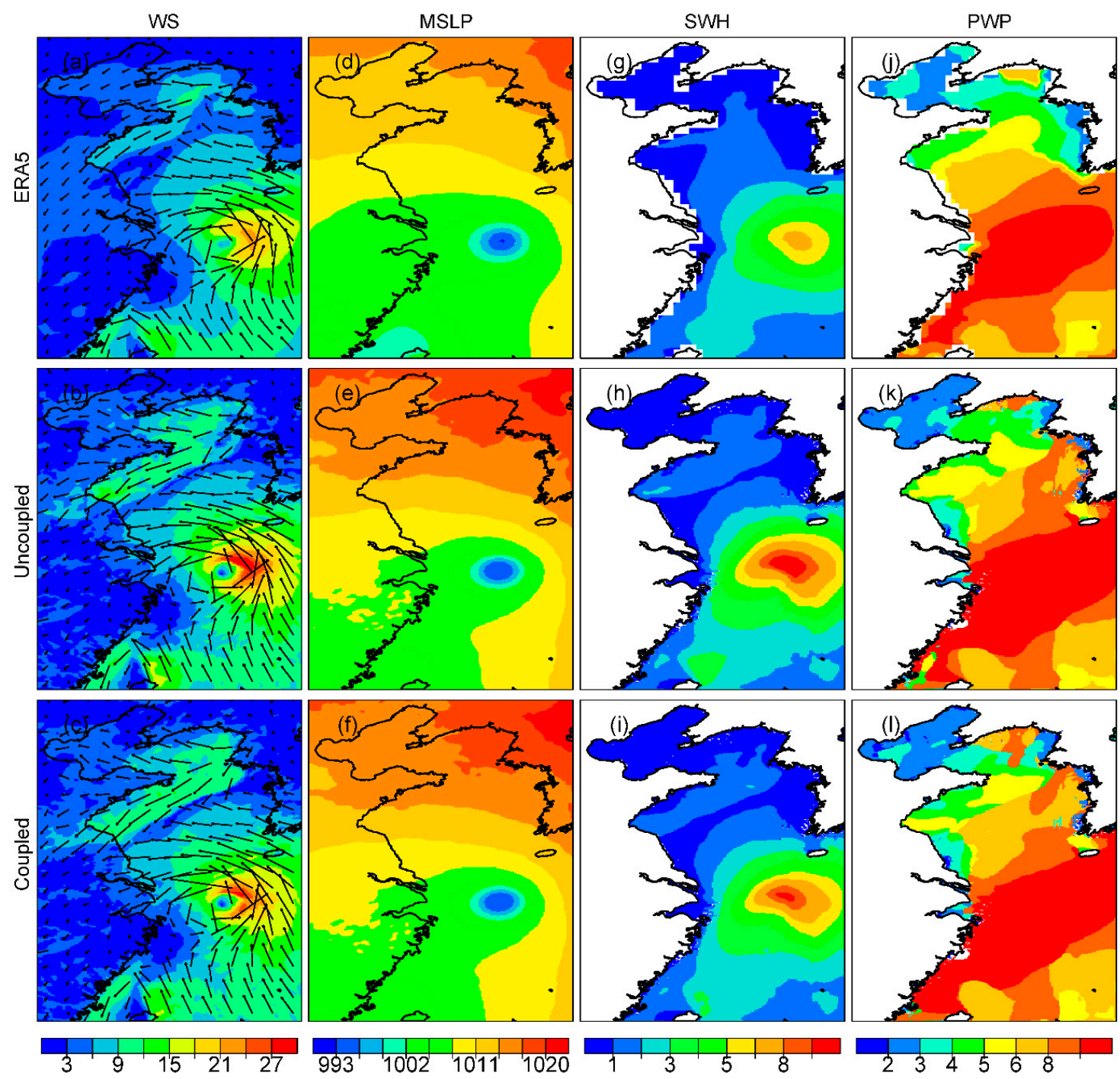

Figure 14. Snapshots of wind speed (WS, $\mathrm{m} / \mathrm{s}$ ) and wind vectors $(\mathbf{a}-\mathbf{c})$, mean sea level pressure (MSLP, hPa, d-f), significant wave height ( $\mathrm{SWH}, \mathrm{m}, \mathbf{g}-\mathbf{i})$ and peak wave period (PWP, s, j-l) for ERA5 reanalysis, uncoupled simulations and coupled simulation at 01:00 UTC, 01 September 2010, when typhoon Kompasu was over the East China Sea. Here, uncoupled represents CCLM for WS and WAM_C for SWH, coupled represents CCLM-WAM for WS and SWH. 
In detail, Figure 14a-c shows that the wind speeds around the typhoon center are $15-24 \mathrm{~m} / \mathrm{s}$ for ERA5. They are generally $18-27 \mathrm{~m} / \mathrm{s}$ for the coupled simulation and can be more than $27 \mathrm{~m} / \mathrm{s}$ for the uncoupled CCLM simulation. Furthermore, due to the high resolution, a strong mesoscale wind band along the coast of the Shandong Peninsula and detailed wind structures over land are generated for both the coupled and the uncoupled simulations. In comparison with the advanced scatterometer (ASCAT) wind speeds (Figure S3), we found that all three simulated data were generally consistent with each other in terms of the spatial patterns of wind biases over water regions. Nevertheless, there were still differences among them: Coupled and uncoupled simulations were better than ERA5 in terms of capturing the wind band over the middle of the Yellow Sea, where the ERA5 greatly underestimated ASCAT winds. However, ERA5 was better fit observations than the CCLM model simulation over parts of the north and the west Yellow Sea, south East China Sea and regions around the center of the typhoon. The general better agreement between ERA5 and ASCAT is because the ASCAT dataset has been assimilated in the ERA5 reanalysis dataset. The large bias of wind intensities around the typhoon center for the coupled and uncoupled simulations is caused by the biased location of the simulated typhoon center compared to ASCAT.

Figure 14d-f shows that the simulated mean sea level pressures (MSLPs) are less than $996 \mathrm{hPa}$. The MSLPs of the coupled and uncoupled simulations are very similar to each other and generally larger than those of ERA5 by approximately $2 \mathrm{hPa}$. The spatial distributions of SWH (Figure 14g-i) are highly consistent with those of wind speeds (Figure 14a-c). The SWH around the typhoon center can reach more than $10 \mathrm{~m}$ for coupled and uncoupled simulations, while those for ERA5 are between 6 and $8 \mathrm{~m}$. For the other regions that are not greatly influenced by typhoon, the SWH is similar among different simulations, with values less than $2 \mathrm{~m}$. In terms of PWP (Figure 14j-1), we see values larger than 6 s over the south Yellow Sea and the East China Sea, while smaller values are seen over the Bohai Sea and part of the north Yellow Sea. Different simulations share similar spatial patterns. The coupled and uncoupled simulations feature larger areas with larger PWP values than those of ERA5, which means that the wave regimes of the former two simulations tend to be dominated by swell. Simulated significant wave height and wave period patterns of WAM_C and CCLM-WAM close to the eastern coast show smaller-scale features due to the wave breaking and refraction that are not captured by the ERA5 wave data.

In addition, atmosphere-wave coupling not only influences the surface atmospheric or wave fields but also has a great impact on the atmospheric fields at high levels. We plotted zonal and meridional cross-sections of wind speed and temperature vertically around the typhoon center (Figure S4) and found that both increases and decreases exist for winds and temperatures in the coupled simulation. However, it seems that the distributions of these changes are rather random. Wind speed differences larger than $6 \mathrm{~m} / \mathrm{s}$ can be found both near the surface and at high levels.

\section{Summary and Discussion}

In this study, we performed several high-resolution simulations over the East China Sea, including a standalone atmospheric CCLM simulation, standalone WAM wave simulations driven by the ERA5 reanalysis dataset (WAM_E) and CCLM simulation outputs (WAM_C), and coupled CCLM-WAM simulation (CCLM-WAM). Two-way coupling is performed interactively using OASIS3-MCT libraries. Based on a series of statistical analyses, the model outputs were validated against in situ and satellite observations in 2010 to assess their skills in simulating wind, wave, and extreme events. This is the first study to downscale the latest ERA5 reanalysis dataset over the ECS. It is also the first study to assess the skills of both a high-resolution atmosphere-wave coupling model and the ERA5 reanalysis dataset in this area. We mainly address three questions. First, can the latest ERA5 reanalysis dataset realistically capture the wind and wave conditions over the East China Sea? Second, what are the added values of the downscaled atmospheric model and wave model to the ERA5 forcing dataset? Third, can wave-atmosphere coupled model outperform standalone wave or atmosphere models in simulating wind or wave features? The answers are summarized as follows: 
(1) ERA5 reanalysis data demonstrate high quality in capturing wind and wave conditions over the ECS except at certain coastal stations. Wind bias is generally less than $0.4 \mathrm{~m} / \mathrm{s}$, wind mean absolute error is less than $1.5 \mathrm{~m} / \mathrm{s}$, and the correlation coefficient is almost 0.9 for satellite observations and larger than 0.75 for station observations. For wave statistics, bias is within $0.1 \mathrm{~m}$, mean absolute error is less than $0.25 \mathrm{~m}$, and the correlation coefficient is generally larger than 0.9 , the normalized standard deviation is around 1. We must note that the satellite data that we used for validations have been assimilated into ERA5. Nevertheless, the ERA5 reanalysis dataset cannot accurately capture the wind speed variability or a probability distribution over the ECS and greatly underestimates the intensities of a strong typhoon event by $20 \mathrm{~m} / \mathrm{s}$.

(2) High-resolution downscaled wave-atmosphere coupled and stand-alone simulations can adequately simulate wind and wave conditions. We found that the downscaled simulations can outperform ERA5 in terms of wind speed variability, wind probability distribution and dominant wind or wave directions. High-resolution downscaled CCLM and CCLM-WAM simulations show higher skill than ERA5 in simulating the intensity of strong typhoons and related mesoscale wind structures. The improvement in wind intensity during typhoon events can reach up to $10 \mathrm{~m} / \mathrm{s}$ by downscaling. Downscaled WAM and CCLM-WAM runs will generate larger significant wave heights and larger peak wave periods than ERA5 during the typhoon event. Our regional downscaled simulations tend to be closer to in situ observations of significant wave height during the typhoon event.

(3) In comparison with satellite observations, the CCLM-WAM simulation outperforms the CCLM in reducing wind bias. The coupled and uncoupled simulations are very similar in terms of other wind and wave statistics. However, by the standalone simulation, the intensity of the typhoon is better simulated than that by the CCLM-WAM simulation. Although there are improvements relative to ERA5, both CCLM-WAM and CCLM underestimate the intensity of the strong typhoon event. Atmosphere-wave coupling not only modifies both surface-atmosphere/wave fields but also greatly impacts atmospheric structures from the surface to upper levels. The wave-stress dependent roughness length for the coupled simulation is consistent with the wind-dependent roughness length for the standalone CCLM simulation under the conditions of old sea and wind speeds less than $8 \mathrm{~m} / \mathrm{s}$, while the former is larger than the latter for wind speeds larger than $10 \mathrm{~m} / \mathrm{s}$ and young wave conditions, which results in relatively weaker annual mean wind speed and significant wave height as well as a weaker intensity of strong typhoons in the coupled simulation than the standalone simulations.

Similar to Wahle et al. [37], we found a general reduction of both surface wind speeds and simulated wave heights from coupling, especially for extreme wind events. However, the standalone CCLM simulation overestimated the storm intensity in Wahle et al. [37], while it underestimated the strong typhoons in this study. Due to the larger roughness length, the coupled simulation tended to result in better agreement with observations for modeling storms over the North Sea and poorer agreement for simulating strong typhoons over the ECS compared to the uncoupled simulation. The different performances of CCLM in capturing storms or typhoons can be probably caused by their different formation mechanisms. Storms over the North Sea derive energy from the horizontal pre-existing thermal contrast in the atmosphere, while typhoons obtain heat energy from the warm moist air over the ocean.

It can be seen that even the latest high-resolution ERA5 reanalysis still underestimate the intensity of strong typhoon. Downscaled CCLM simulations with 7-km resolution as in the present study can greatly improve the skills in capturing the intenstiy of strong typhoons, however, large underestimation still exists for high-resolution downscaling, as in some other studies $[65,66]$. In contrast, there is overestimation of typhoon intensities by different high-resolution models [67]. To realistically simulate tropical cyclone intensity, we suggest implementing an atmosphere-wave-ocean coupled model system [68], and some key interaction processes, such as wave breaking-induced sea spray and wave breaking-induced mixing, should be considered [21].

In the present study, the roughness length/drag coefficient parameterization of the CCLM model is calculated from the Charnock parameter, which depends on the sea state through the wave-induced 
stress for the coupled model. The parameterization methods are kept consistent with the ECMWF coupled model system to better identify the added value from the high-resolution atmosphere-wave coupling to ERA5. Subsequently, for simulating tropical cyclones over the East China Sea, further sensitivity experiments should be conducted to test the skills of different roughness length/drag coefficient parameterizations, such as wave age-dependent or wave steepness-dependent factors (e.g., $[28,29,33,35])$. The optimal coupling system is expected to be derived based on a series of experiments and contributes to the improvement of modeling accuracy, especially in the cases of strong typhoons. Finally, there are considerable discrepancies among the different observational datasets in capturing specific wind or wave features. Therefore, a careful selection of observation datasets as a reference is recommended to assess the validation of model performance.

Supplementary Materials: The following are available online at http://www.mdpi.com/2073-4433/11/3/252/s1, Figure S1: Schematic diagram of the CCLM-WAM coupled model, Figure S2: Tracks of Jason-1 and Jason-2 over the East China Sea in 2010 for wind speeds (m/s), Figure S3: Snapshots at 01:00 UTC, 01 September 2010 for (a) Wind speed (shaded, $\mathrm{m} / \mathrm{s}$ ) and vectors of ASCAT satellite, (b-d) wind speed bias (m/s) of ERA5, uncoupled simulation and coupled simulation against ASCAT observations over the East China Sea, Figure S4: Zonal $(a, c)$ and meridional $(b, d)$ cross sections of typhoon center at 0900 UTC 01 September 2010 for horizontal wind speed (shaded) and temperature (contours) of CCLM (upper panel) and CCLM-WAM (middle panel) simulations and the differences between CCLM-WAM and CCLM (bottom panel).

Author Contributions: Conceptualization, D.L., J.S. and B.Y.; methodology, S.G. and A.B.; validation, D.L. and J.F.; formal analysis, D.L. and J.S.; resources, J.S. and B.Y.; writing—original draft preparation, D.L.; writing-review and editing, J.S., B.Y. and J.F.; visualization, D.L.; supervision, J.S. and B.Y. All authors have read and agreed to the published version of the manuscript.

Funding: Funding for this study was provided by the National Key Research and Development Program of China (2017YFA0604100), the National Natural Science Foundation of China (41706019, 41706020) and NSFC-Shandong Joint Fund (U1806227). SG and JS acknowledge the funding by Initiative and Networking Fund of the Helmholtz Association through the project "Advanced Earth System Modelling Capacity (ESM), JS and AB acknowledge CLICCS Center of Excellence Project Topic A6, AB acknowledges CMEMS- SE WaveFlow Project.

Acknowledgments: We thank the German Climate Computing Center (DKRZ) for providing the computation time for our simulations. We acknowledge the Marine Science Data Center of the Chinese Academy of Sciences and the National Oceanographic Data Center of the US for providing observation data. We acknowledge the "Advanced Earth System Modelling Capacity (ESM) and CLICCS Center of Excellence projects. The authors thank Anne Wiese for her valuable discussions and Gerhard Geyer for helping with satellite observations.

Conflicts of Interest: The authors declare no conflict of interest.

\section{References}

1. Warner, J.C.; Armstrong, B.; Sylvester, C.S.; Voulgaris, G.; Nelson, T.; Schwab, W.C.; Denny, J.F. Storm-induced inner-continental shelf circulation and sediment transport: Long Bay, South Carolina. Cont. Shelf Res. 2012, 42, 51-63. [CrossRef]

2. Pullen, J.; Caldeira, R.; Doyle, J.D.; May, P.; Tomé, R. Modeling the air-sea feedback system of Madeira Island. J. Adv. Modeling Earth Syst. 2017, 9, 1641-1664. [CrossRef]

3. Kumar, N.; Voulgaris, G.; Warner, J.C.; Olabarrieta, M. Implementation of the vortex force formalism in the coupled ocean-atmosphere-wave-sediment transport (COAWST) modeling system for inner shelf and surf zone applications. Ocean Model. 2012, 47, 65-95. [CrossRef]

4. Olabarrieta, M.; Warner, J.C.; Armstrong, B.; Zambon, J.B.; He, R. Ocean-atmosphere dynamics during Hurricane Ida and Nor'Ida: An application of the coupled ocean-atmosphere-wave-sediment transport (COAWST) modeling system. Ocean Model. 2012, 43, 112-137. [CrossRef]

5. Zambon, J.B.; He, R.; Warner, J.C. Investigation of hurricane Ivan using the coupled ocean-atmosphere-wave-sediment transport (COAWST) model. Ocean Dyn. 2014, 64, 1535-1554. [CrossRef]

6. Ferrari, R.; Wunsch, C. Ocean Circulation Kinetic Energy: Reservoirs, Sources, and Sinks. Annu. Rev. Fluid Mech. 2009, 41, 253-282. [CrossRef]

7. Pineau-Guillou, L.; Ardhuin, F.; Bouin, M.N.; Redelsperger, J.L.; Chapron, B.; Bidlot, J.R.; Quilfen, Y. Strong winds in a coupled wave-atmosphere model during a North Atlantic storm event: Evaluation against observations. Q. J. R. Meteorol. Soc. 2018, 144, 317-332. [CrossRef] 
8. Cavaleri, L.; Fox-Kemper, B.; Hemer, M. Wind Waves in the Coupled Climate System. Bull. Am. Meteorol. Soc. 2012, 93, 1651-1661. [CrossRef]

9. Janssen, P.A.; Breivik, Ø.; Mogensen, K.; Vitart, F.; Balmaseda, M.; Bidlot, J.-R.; Keeley, S.; Leutbecher, M.; Magnusson, L.; Molteni, F. Air-Sea Interaction and Surface Waves; European Centre for Medium-Range Weather Forecasts: Reading, UK, 2013.

10. Schrum, C. Regional Climate Modeling and Air-Sea Coupling. In Oxford Research Encyclopedia of Climate Science; von Storch, H., Ed.; Oxford University Press: Oxford, UK, 2017.

11. Li, D.; von Storch, H.; Geyer, B. Testing reanalyses in constraining dynamical downscaling. J. Meteorol. Soc. Jpn. Ser. II 2016, 94, 47-68. [CrossRef]

12. Zweers, N.; Makin, V.; De Vries, J.; Burgers, G. A sea drag relation for hurricane wind speeds. Geophys. Res. Lett. 2010, 37. [CrossRef]

13. Feser, F.; von Storch, H. A dynamical downscaling case study for typhoons in Southeast Asia using a regional climate model. Mon. Weather Rev. 2008, 136, 1806-1815. [CrossRef]

14. Li, D.; von Storch, H.; Geyer, B. High-resolution wind hindcast over the Bohai Sea and the Yellow Sea in East Asia: Evaluation and wind climatology analysis. J. Geophys. Res. Atmos. 2016, 121, 111-129. [CrossRef]

15. Cavaleri, L.; Bertotti, L. Accuracy of the modelled wind and wave fields in enclosed seas. Tellus A Dyn. Meteorol. Oceanogr. 2004, 56, 167-175. [CrossRef]

16. Van Vledder, G.P.; Akpınar, A. Wave model predictions in the Black Sea: Sensitivity to wind fields. Appl. Ocean Res. 2015, 53, 161-178. [CrossRef]

17. Wiese, A.; Staneva, J.; Schulz-Stellenfleth, J.; Behrens, A.; Fenoglio-Marc, L.; Bidlot, J.-R. Synergy of wind wave model simulations and satellite observations during extreme events. Ocean Sci. 2018, 14, 1503-1521. [CrossRef]

18. Pryor, S.; Hahmann, A.N. Downscaling Wind. In Oxford Research Encyclopedia of Climate Science; von Storch, H., Ed.; Oxford University Press: Oxford, UK, 2019.

19. Cavaleri, L.; Bertotti, L. The improvement of modelled wind and wave fields with increasing resolution. Ocean Eng. 2006, 33, 553-565. [CrossRef]

20. Du, J.; Bolaños, R.; Guo Larsén, X. The use of a wave boundary layer model in SWAN. J. Geophys. Res. Ocean. 2017, 122, 42-62. [CrossRef]

21. Zhao, B.; Qiao, F.; Cavaleri, L.; Wang, G.; Bertotti, L.; Liu, L. Sensitivity of typhoon modeling to surface waves and rainfall. J. Geophys. Res. Ocean. 2017, 122, 1702-1723. [CrossRef]

22. Rizza, U.; Canepa, E.; Ricchi, A.; Bonaldo, D.; Carniel, S.; Morichetti, M.; Passerini, G.; Santiloni, L.; Scremin Puhales, F.; Miglietta, M.M. Influence of wave state and sea spray on the roughness length: Feedback on medicanes. Atmosphere 2018, 9, 301. [CrossRef]

23. Edson, J.B.; Jampana, V.; Weller, R.A.; Bigorre, S.P.; Plueddemann, A.J.; Fairall, C.W.; Miller, S.D.; Mahrt, L.; Vickers, D.; Hersbach, H. On the exchange of momentum over the open ocean. J. Phys. Oceanogr. 2013, 43, 1589-1610. [CrossRef]

24. Donelan, M.; Haus, B.K.; Reul, N.; Plant, W.; Stiassnie, M.; Graber, H.C.; Brown, O.; Saltzman, E. On the limiting aerodynamic roughness of the ocean in very strong winds. Geophys. Res. Lett. 2004, 31. [CrossRef]

25. Larsén, X.G.; Makin, V.K.; Smedman, A.-S. Impact of waves on the sea drag: Measurements in the Baltic Sea and a model interpretation. Glob. Atmos. Ocean Syst. 2003, 9, 97-120. [CrossRef]

26. Toba, Y.; Iida, N.; Kawamura, H.; Ebuchi, N.; Jones, I.S. Wave dependence of sea-surface wind stress. J. Phys. Oceanogr. 1990, 20, 705-721. [CrossRef]

27. Drennan, W.M.; Taylor, P.K.; Yelland, M.J. Parameterizing the sea surface roughness. J. Phys. Oceanogr. 2005, 35, 835-848. [CrossRef]

28. Taylor, P.K.; Yelland, M.J. The dependence of sea surface roughness on the height and steepness of the waves. J. Phys. Oceanogr. 2001, 31, 572-590. [CrossRef]

29. Drennan, W.M.; Graber, H.C.; Hauser, D.; Quentin, C. On the wave age dependence of wind stress over pure wind seas. J. Geophys. Res. Ocean. 2003, 108. [CrossRef]

30. Hemer, M.A.; Wang, X.L.L.; Weisse, R.; Swail, V.R. Advancing Wind-Waves Climate Science The COWCLIP Project. Bull. Am. Meteorol. Soc. 2012, 93, 791-796. [CrossRef]

31. Bruneau, N.; Toumi, R. A fully-coupled atmosphere-ocean-wave model of the Caspian Sea. Ocean Model. 2016, 107, 97-111. [CrossRef] 
32. Charles, E.; Hemer, M. Parameterization of a wave-dependent surface roughness: A step towards a fully coupled atmosphere-ocean-sea ice-wave system. In Proceedings of the 13th International Workshop on Wave Hindcasting and Forecasting and 4th Coastal Hazard Symposium, Banff, AB, Canada, 27 October-1 November 2013.

33. Fan, Y.; Lin, S.-J.; Held, I.M.; Yu, Z.; Tolman, H.L. Global ocean surface wave simulation using a coupled atmosphere-wave model. J. Clim. 2012, 25, 6233-6252. [CrossRef]

34. Larsén, X.G.; Du, J.; Bolaños, R.; Imberger, M.; Kelly, M.C.; Badger, M.; Larsen, S. Estimation of offshore extreme wind from wind-wave coupled modeling. Wind Energy 2019. [CrossRef]

35. Shimura, T.; Mori, N.; Takemi, T.; Mizuta, R. Long-term impacts of ocean wave-dependent roughness on global climate systems. J. Geophys. Res. Ocean. 2017, 122, 1995-2011. [CrossRef]

36. Varlas, G.; Katsafados, P.; Papadopoulos, A.; Korres, G. Implementation of a two-way coupled atmosphere-ocean wave modeling system for assessing air-sea interaction over the Mediterranean Sea. Atmos. Res. 2018, 208, 201-217. [CrossRef]

37. Wahle, K.; Staneva, J.; Koch, W.; Fenoglio-Marc, L.; Ho-Hageman, H.T.M.; Stanev, E.V. An atmosphere-wave regional coupled model: Improving predictions of wave heights and surface winds in the southern North Sea. Ocean Sci. 2017, 13, 289-301. [CrossRef]

38. Doyle, J.D. Coupled ocean wave/atmosphere mesoscale model simulations of cyclogenesis. Tellus Ser. A Dyn. Meteorol. Oceanogr. 2002, 47, 766-778. [CrossRef]

39. Lionello, P.; Malguzzi, P.; Buzzi, A. Coupling between the Atmospheric Circulation and the Ocean Wave Field: An Idealized Case. J. Phys. Oceanogr. 1998, 28, 161-177. [CrossRef]

40. Bao, J.; Wilczak, J.; Choi, J.; Kantha, L. Numerical simulations of air-sea interaction under high wind conditions using a coupled model: A study of hurricane development. Mon. Weather Rev. 2000, 128, 2190-2210. [CrossRef]

41. Katsafados, P.; Papadopoulos, A.; Korres, G.; Varlas, G. A fully coupled atmosphere-ocean wave modeling system for the Mediterranean Sea: Interactions and sensitivity to the resolved scales and mechanisms. Geosci. Model Dev. 2016, 9. [CrossRef]

42. Hersbach, H.; Dee, D. ERA5 reanalysis is in production. ECMWF Newsl. 2016, 147, 5-6.

43. Rockel, B.; Will, A.; Hense, A. The Regional Climate Model COSMO-CLM(CCLM). Meteorol. Z. 2008, 17, 347-348. [CrossRef]

44. Schättler, U.; Doms, G.; Schraff, C. A description of the nonhydrostatic regional COSMO-model part VII: User's guide. Dtsch. Wetterd. Rep. COSMO-Model 2008, 4, 142.

45. Von Storch, H.; Langenberg, H.; Feser, F. A spectral nudging technique for dynamical downscaling purposes. Mon. Weather Rev. 2000, 128, 3664-3673. [CrossRef]

46. Li, D.L.; Yin, B.S.; Feng, J.L.; Dosio, A.; Geyer, B.; Qi, J.F.; Shi, H.Y.; Xu, Z.H. Present Climate Evaluation and Added Value Analysis of Dynamically Downscaled Simulations of CORDEX-East Asia. J. Appl. Meteorol. Clim. 2018, 57, 2317-2341. [CrossRef]

47. Group, T.W. The WAM model-A third generation ocean wave prediction model. J. Phys. Oceanogr. 1988, 18, 1775-1810. [CrossRef]

48. Staneva, J.; Alari, V.; Breivik, O.; Bidlot, J.R.; Mogensen, K. Effects of wave-induced forcing on a circulation model of the North Sea. Ocean Dynam 2017, 67, 81-101. [CrossRef]

49. Hersbach, H.; Janssen, P. Improvement of the short-fetch behavior in the Wave Ocean Model (WAM). J. Atmos. Ocean. 1999, 16, 884-892. [CrossRef]

50. Bidlot, J.; Janssen, P.; Abdalla, S.; Hersbach, H. A Revised Formulation of Ocean Wave Dissipation and Its Model Impact; ECMWF: Reading, UK, 2007.

51. Gridded Bathymetry Data. Available online: https://www.gebco.net/data_and_products/gridded_ bathymetry_data/ (accessed on 22 January 2020).

52. Valcke, S. The OASIS3 coupler: A European climate modelling community software. Geosci. Model Dev. 2013, 6, 373-388. [CrossRef]

53. What Are the Changes from ERA-Interim to ERA5? Available online: https://confluence.ecmwf.int/pages/ viewpage.action?pageId=74764925 (accessed on 2 March 2020).

54. Charnock, H. Wind stress on a water surface. Q. J. R. Meteorol. Soc. 1955, 81, 639-640. [CrossRef] 
55. Doms, G.; Förstner, J.; Heise, E.; Herzog, H.; Mironov, D.; Raschendorfer, M.; Reinhardt, T.; Ritter, B.; Schrodin, R.; Schulz, J.-P. A description of the nonhydrostatic regional COSMO model. Part II: Physical parameterization. Dtsch. Wetterd. Offenb. Ger. 2011, 1-161.

56. Janssen, P.A. Quasi-linear theory of wind-wave generation applied to wave forecasting. J. Phys. Oceanogr. 1991, 21, 1631-1642. [CrossRef]

57. ECMWF. IFS Documentation CY45R1; ECMWF: Reading, UK, 2018.

58. Wu, J. Wind-stress coefficients over sea surface from breeze to hurricane. J. Geophys. Res. Ocean. 1982, 87, 9704-9706. [CrossRef]

59. Taylor, K.E. Summarizing multiple aspects of model performance in a single diagram. J. Geophys. Res. Atmos. 2001, 106, 7183-7192. [CrossRef]

60. Global Hazards-September 2010. Available online: https://www.ncdc.noaa.gov/sotc/hazards/201009 (accessed on 22 January 2020).

61. RSMC Best Track Data (Text). Available online: http://www.jma.go.jp/jma/jma-eng/jma-center/rsmc-hp-pubeg/besttrack.html (accessed on 22 January 2020).

62. CMA Tropical Cyclone Data Center for the western North Pacific Basin. Available online: http://tcdata. typhoon.org.cn/en/zjljsjj_zlhq.html (accessed on 22 January 2020).

63. Robusto, C.C. The cosine-haversine formula. Am. Math. Mon. 1957, 64, 38-40. [CrossRef]

64. Feser, F.; von Storch, H. Regional modelling of the western Pacific typhoon season 2004. Meteorol. Z. 2008, 17, 519-528. [CrossRef]

65. Kanada, S.; Wada, A. Sensitivity to horizontal resolution of the simulated intensifying rate and inner-core structure of typhoon Ida, an extremely intense typhoon. J. Meteorol. Soc. Jpn. Ser. II 2016, 94, 181-190. [CrossRef]

66. Sun, J.; He, H.; Hu, X.; Wang, D.; Gao, C.; Song, J. Numerical Simulations of Typhoon Hagupit (2008) Using WRF. Weather Forecast. 2019, 34, 999-1015. [CrossRef]

67. Mogensen, K.S.; Magnusson, L.; Bidlot, J.R. Tropical cyclone sensitivity to ocean coupling in the ECMWF coupled model. J. Geophys. Res. Ocean. 2017, 122, 4392-4412. [CrossRef]

68. Ricchi, A.; Miglietta, M.M.; Bonaldo, D.; Cioni, G.; Rizza, U.; Carniel, S. Multi-physics ensemble versus Atmosphere-Ocean coupled model simulations for a tropical-like cyclone in the Mediterranean Sea. Atmosphere 2019, 10, 202. [CrossRef]

(C) 2020 by the authors. Licensee MDPI, Basel, Switzerland. This article is an open access article distributed under the terms and conditions of the Creative Commons Attribution (CC BY) license (http://creativecommons.org/licenses/by/4.0/). 